\title{
Energy, water and process technologies integration for the simultaneous production of ethanol and food from the entire corn plant
}

\author{
Lidija Čuček1, Mariano Martín², Ignacio E. Grossmann 22, Zdravko Kravanja*1 \\ ${ }^{1}$ Faculty of Chemistry and Chemical Engineering. University of Maribor. Maribor 2000, Slovenia \\ ${ }^{2}$ Department of Chemical Engineering. Carnegie Mellon University. Pittsburgh PA, 15213, USA
}

\begin{abstract}
This paper presents simultaneous integration of different technologies such as the traditional dry-grind process to obtain ethanol from grain with the gasification of the corn stover followed by either syngas fermentation or catalytic mixed alcohols synthesis. The best integrated process when using the entire corn plant (18 kg/s of grain and $10.8 \mathrm{~kg} / \mathrm{s}$ of stover) is the one in which the dry-grind technology to process corn grain is integrated with the catalytic path for the corn stover due to the better integration of energy, requiring only $18 \mathrm{MW}$ of energy, $51 \mathrm{MW}$ of cooling and $2 \mathrm{gal} / \mathrm{gal}$ of freshwater, for an ethanol production cost of $1.2 \$ /$ gal. However, the production cost decreases as we only use stover to produce ethanol, while the grain is used for food due to the lower cost of the stover and the more favorable energy balance of the ethanol production process from gasification.
\end{abstract}

Keywords: Bioethanol; Energy and Food Production; Integrated Process Synthesis; Heat, Water and Technology Integration; Process Synthesizer MIPSYN

\footnotetext{
* Corresponding author. Tel.: +386 22294 481; Fax: +386 22527774 .

Email address: kravanja@uni-mb.si
} 


\section{1.-Introduction}

Ethanol from biomass has become one of the most important alternatives to gasoline due to its compatibility with current automobile engines (Cole, 2007) and to the fact that it can take advantage of the existing supply chain of liquid fuels that is already well established.

The first generation ethanol uses corn grain to obtain the sugars that are fermented to ethanol following the dry-grind process (Jacques et al., 1999). Ethanol from corn grain represents $95 \%$ of the ethanol produced in the US, see Figure 1, providing $0.5 \%$ of transportation fuels and using $6 \%$ of the annual production of corn.

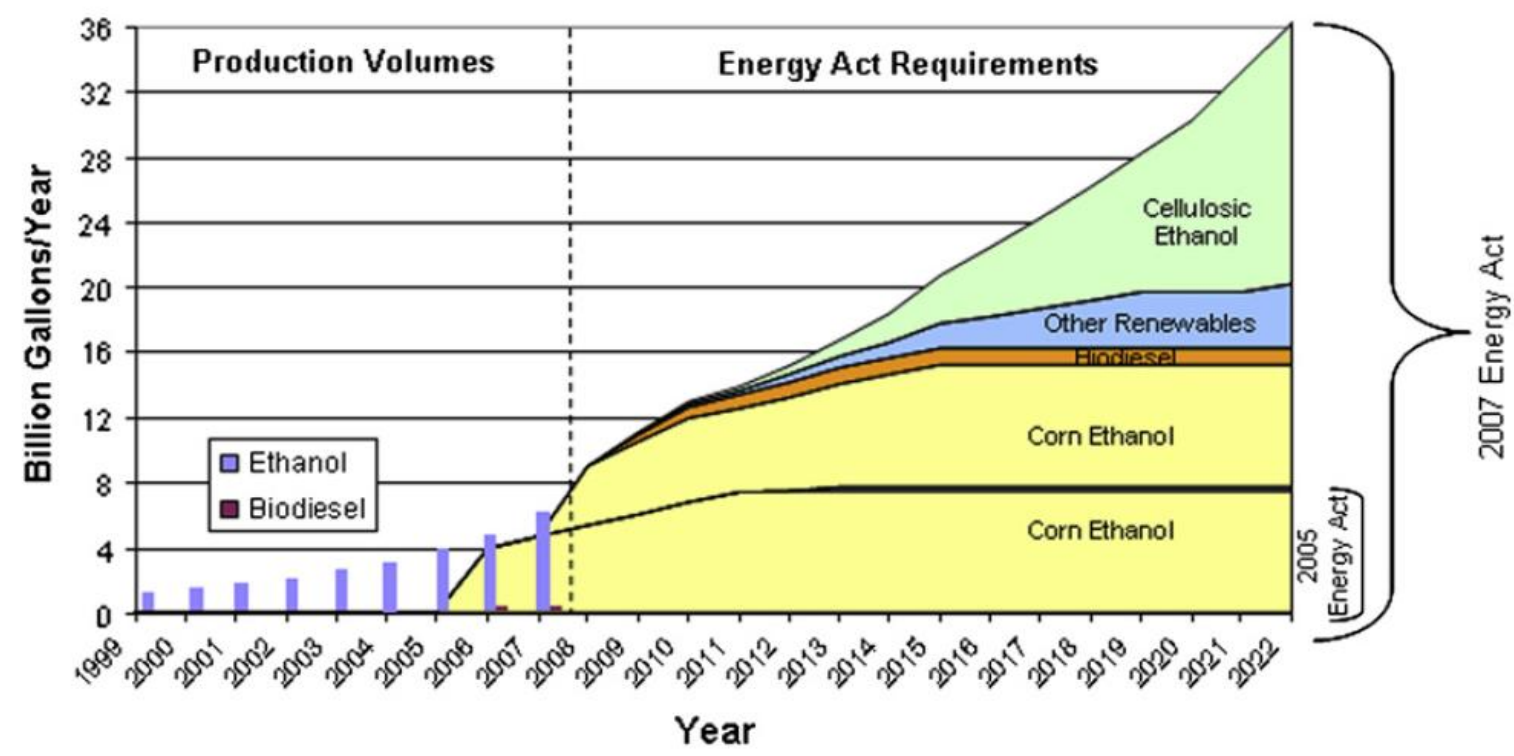

Figure 1.- Bioethanol Production expectations (source US DOE)

However, there are limits to how much ethanol can be produced from corn grain because it interferes with the food supply chain affecting the food prices. Furthermore, the production of first generation ethanol has raised questions regarding its technological feasibility as an alternative fuel in terms on land, energy demand, water consumption (Elcock, 2008; Ferguson, 2003, 2004; Shapouri et al., 1995, 2002, 2004; Pimentel, 1998, 2001, 2003). Thus the so called second generation of biofuels has received worldwide attention in order to improve the yields, reduce the consumption of utilities in the production process, while using a raw material that does not compete with food. In the longer run it is expected that energy crops with higher yield to ethanol such as switchgrass or hybrid poplar become the feedstocks for the largest quantity of ethanol. However, in the current 
harvesting of corn not only corn grain is obtained but corn stover, the lignocellulosic part of the plant which can also be used as raw material to produce ethanol, as seen in Figure 2 .

On average corn grain accounts for about $45 \%$ of the total dry matter yield of a corn field. However, the remaining $55 \%$ can also be used as raw material for fuel, even though it is not possible to harvest more than $70 \%$ so that there is enough cover of the ground in the form of leaves and husks to avoid erosion (Nielsen, 2009; Atchison and Hettenhaus, 2003). Therefore, corn stover provides a logical bridge between corn grain and energy crops, in part because no additional crop needs to be planted. Presently less than $10 \%$ of corn stover is collected. Furthermore, corn stover is close to existing corn grain-to-ethanol production facilities. Estimates of annual collectible corn stover based on soil erosion models are in the range of 100 to 120 million dry metric tons per year, which would produce approximately 30 billion liters ( 8 billion gallons) of ethanol (Bozell and Landucci, 1993; DiPardo, 2000; lowa Department of Natural Resources, 2000; Walsh et al., 2000). The concept of whole crop biorefinery is illustrated in Figure 2.

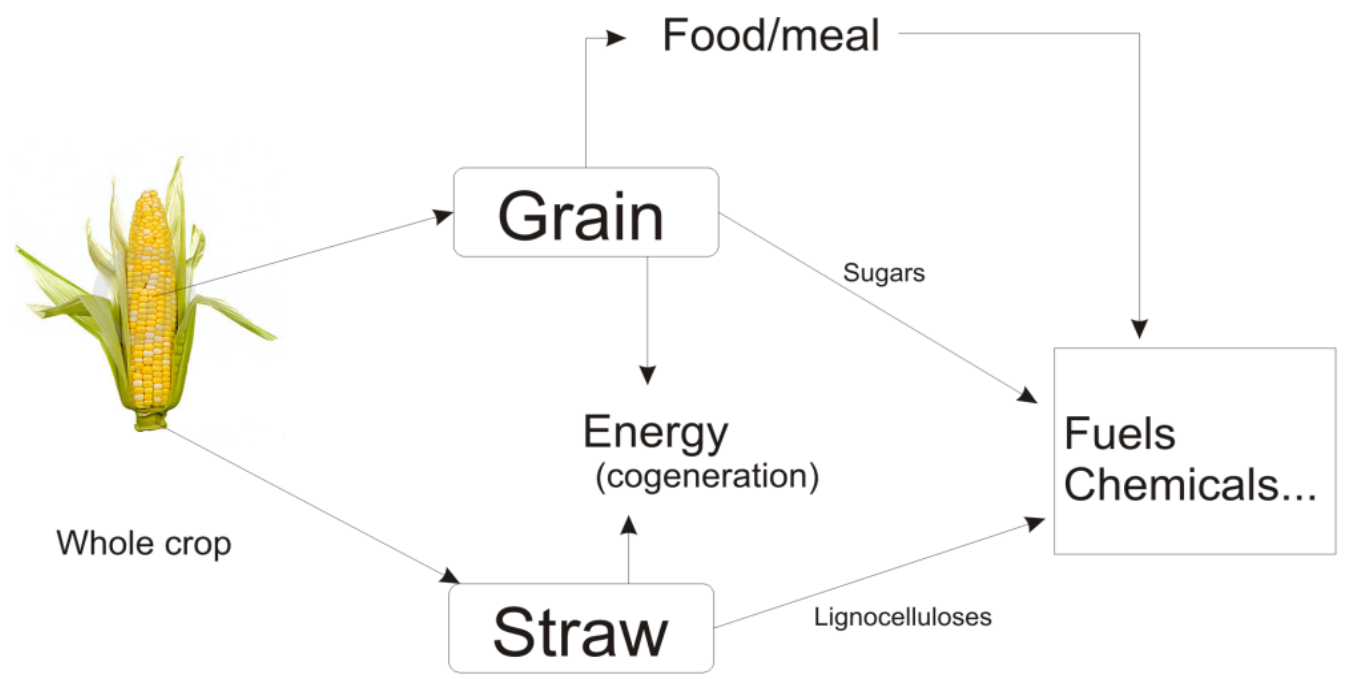

Figure 2.- Whole plant biorefinery.

Two types of process technologies can be used to transform lignocellulosic raw materials into ethanol. The first one is based on the hydrolysis of the raw material to break down the physical and chemical structure of the crops to expose the sugars that are fermented to ethanol. Due to its similarity with the current production of ethanol and the expected lower capital cost, this technology has received the attention of many researchers (Hamelinck, 2005; Cardona and Sánchez, 2006; Keshwani and Cheng, 2009; Zhang, 2009). The main 
disadvantage of the hydrolysis of the lignocellulosic material is the fact that lignin cannot be processed and thus a part of the carbon source of the raw material cannot be used to obtain ethanol. The second technology is based on the gasification of the raw material into syngas which is used to obtain ethanol either via a Fischer-Tropsch based catalytic reaction or via fermentation of the syngas (Phillips et al., 2007; Huhnke, 2008; Piccolo and Bezzo, 2009; Zhu et al., 2009). This alternative works at higher temperature and provides scope for energy integration with the production process that uses the grain.

In order to design a biorefinery that is capable of fully using the entire plant, an integrated design of drygrind and gasification technologies is proposed using the process simulator MIPSYN, Mixed-Integer Process SYNthesizer (Kravanja, 2010). The aim of the paper is to optimize the integrated biorefinery that uses the entire corn plant by integrating the technologies required to process the corn grain and the corn stover in such a way that equipment can be shared and most importantly, energy can be integrated due to the high demand of energy in the dry-grind process. In a second stage, we design the optimal water treatment network using the model by Ahmetović and Grossmann (2010).

\section{2.-Problem statement}

We propose an integrated process for the production of ethanol from corn grain and corn stover, based on the results by previous papers by Karuppiah et al. (2008) and Martín and Grossmann (2010) in order to make full use of the corn plant. We model the superstructure in the process simulator MIPSYN (Kravanja and Grossmann, 1990, 1994)

MIPSYN, successor of PROSYN, is an implementation of the modeling and decomposition (M/D) strategy developed by Kocis and Grossmann (1989) and the outer-approximation and equality-relaxation algorithm (OA/ER) by Kocis and Grossmann (1987). MIPSYN enables automated execution of simultaneous topology and parameter optimization of processes enabling the solution of large scale MINLP problems. For the simultaneous optimization and heat integration, we use the model by Duran and Grossmann (1986) that is already implemented in MIPSYN. Figure 3 shows the scheme for the algorithm implemented in MIPSYN. 


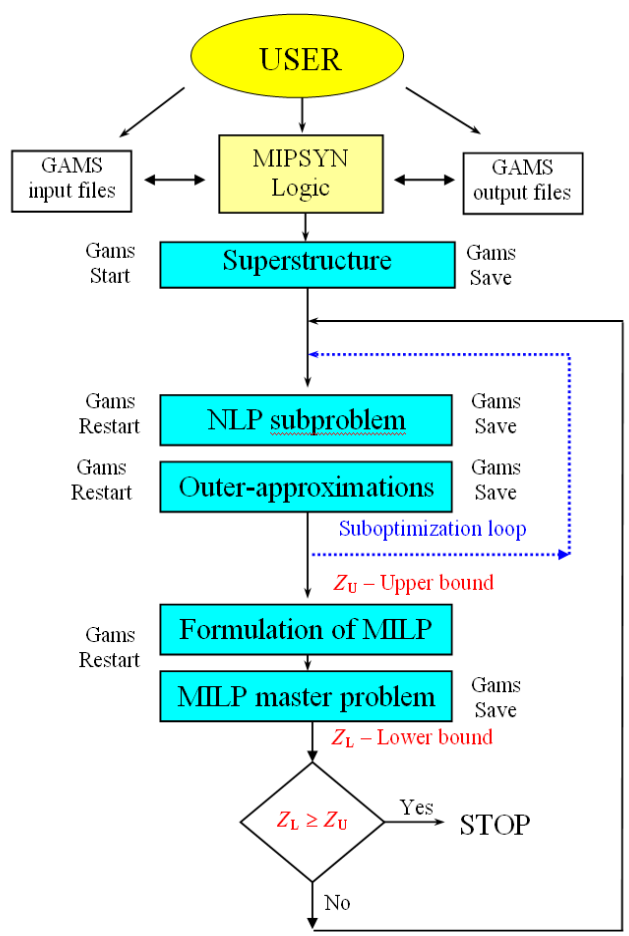

Figure 3.- Scheme of the algorithm used by MIPSYN (Kravanja, 2010)

Finally, for the best integrated process, we design the optimal water network using the model proposed by Ahmetović and Grossmann (2010).

The paper is organized as follows. In section 3 we first describe the processes considered for the production of ethanol, biochemical path from corn grain, and thermo-chemical or thermo-biochemical paths for the lignocellulosic material of the corn plants and the integrated flowsheet. Next, we describe the characteristics of the water network such as process and treatment units. In section 4, we present the results from the optimization of the integrated superstructure in terms of technologies and energy, and the water network design. We also present the effect that the use of different ratios of grain and stover has in the integration of the processes. Finally in section 5 , we present some conclusions on the solution found compared to previous studies on water consumption and production processes and costs (Martín et al., 2010; Martín and Grossmann, 2010).

\section{3.- Integrated technology description}

\section{1.-Dry-grind process}

Based on the paper from Karrupiah et al. (2008), the optimized corn ethanol production plant consists of three parts. First, the corn grain structure is broken by a series of thermal pretreatments that are capable of 
disintegrating the physical structure so that sugars are exposed in a second stage by using biochemical treatment, liquefaction and sacharification. The second part of the process consists of the fermentation of the sugars towards the generation of ethanol. The solids are separated before the beer column and, once dried, a product, DDGS (Dried Distillers Grains with Solubles), that can be used as cattle feed, is obtained contributing to the economics of the process. The liquid phase, mainly ethanol and water, is sent to dehydration where by using distillation columns, corn grits and molecular sieves, fuel quality ethanol is obtained. For further details of the model we refer to Karuppiah et al. (2008).

\section{2.-Lignocellulosic based ethanol via gasification}

The structure of the process is based on the results presented by Martín and Grossmann (2010) where the production of ethanol from lignocellulosic materials, switchgrass, is optimized. In order to produce ethanol, the corn stover is gasified at high pressure with steam and oxygen. The gas is cleaned from solids and chemicals in a series of stages. First, the char is removed using a cyclone. Next, the hydrocarbons generated in the gasification of the corn stover are reformed with steam and gas is purified following the hot cleaning technology based on filters. The composition of the gas is adjusted in terms of $\mathrm{CO}$ and $\mathrm{H}_{2}$, so that the molar ratio becomes 1 , which results in the production of hydrogen, an important asset for the economics of the process. Next, sour gases are removed. It was found that the optimal process consists of using a combined technology based on Pressure Swing Adsorption (PSA), which mainly removes $\mathrm{CO}_{2}$, and monoethanolamine (MEA), which can also remove $\mathrm{H}_{2} \mathrm{~S}$ depending on the synthetic path. Two synthetic paths are proposed for this superstructure, either the fermentation of the syngas or the catalytic production of alcohols. The $\mathrm{H}_{2} \mathrm{~S}$ is poisonous for the catalysts and must be removed, while the bacteria used can handle concentrations below $2.5 \%$. By using the fermentation path, ethanol is mainly produced and the resulting mixture of water and ethanol is to be dehydrated. We propose to share the technologies used for the corn grain based process to obtain fuel grade ethanol. In the case of using the catalytic path, a mixture of alcohols is produced, mainly methanol, ethanol and propanol, which is separated using a sequence of distillation columns. Further details of the models of the units can be found in the above mentioned paper (Martín and Grossmann, 2010). 


\section{3.-Integration of the processes}

In Figure 4 we show the proposed superstructure for the integrated process. The corn harvested consists of the grain and the lignocellulosic material stover. The integration begins with the use of the raw material (entire corn plant). The grain follows the path described in a previous paper (Karuppiah et al., 2008), while the stover is treated using gasification. Next, technologies are shared between the biochemical and the thermo-biochemical processes such as the same dehydration path, as well as between the biochemical and the thermal paths like the carbon capture process units. Finally, energy is integrated in the process so that hot streams of the thermo-chemical process are used to provide energy to the in general low temperature process streams of the biochemical process.

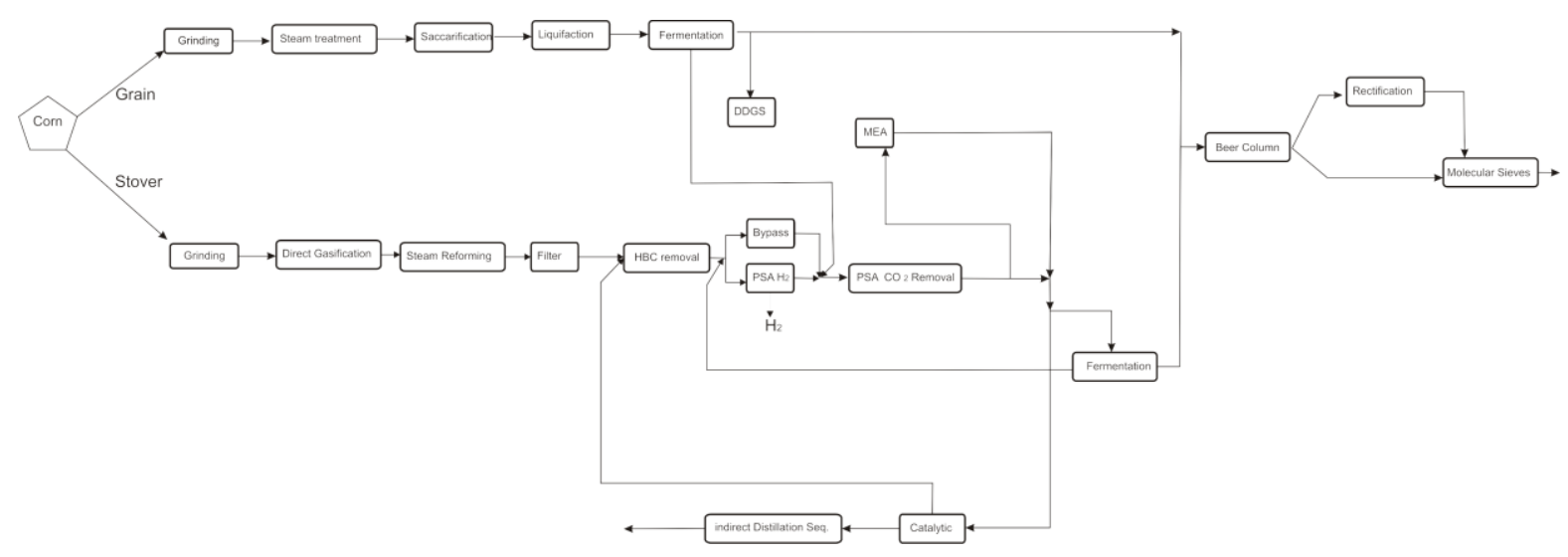

Figure 4.- Superstructure of the process. (Complete page size)

In order to model the different equipment involved, the same models presented in previous papers are used. In the case of the more complex equipment, short-cuts models have been obtained, e.g. for the gasifier, the tar removal and the catalytic reactor using the more detailed models in Martín and Grossmann (2010) but using corn stover instead of switchgrass whose composition is taken from the literature (Jablonski et al., 2009). These models provide the output concentration and the heat balance as a function of the inlet flow. Furthermore, there are some modifications to simulate the partial condensation of water in several heat exchangers, which is key in the water balance of the process, where a superstructure is defined consisting of a separation where we define the humidity of the gas and the water that is condensed so that total condensers and coolers are used from the model library already available is MIPSYN. Figure 5 shows the scheme of the partial condenser, where the vapor phase is calculated based on the maximum moisture of the gas at that pressure and temperatures. 


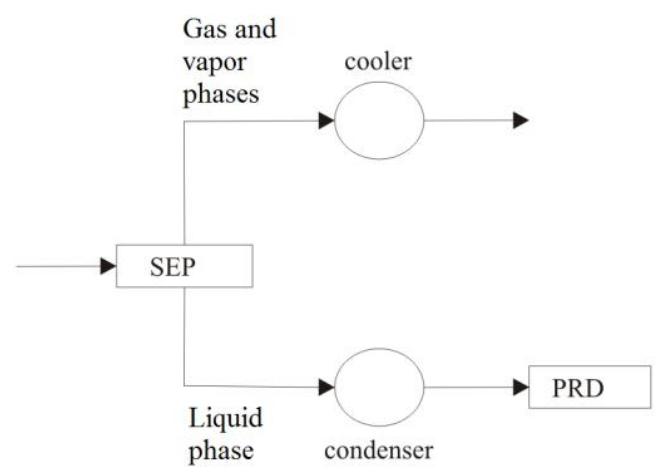

Figure 5.- Detail of the partial condenser modeling

\section{4.-Water integration}

The low cost of freshwater prevents from a proper water optimization if it is incorporated in the economic objective function for the optimization of the superstructure. Thus, a sequential approach is used in which we design the optimal water network for the optimized integrated corn ethanol production process using the model proposed by Ahmetović and Grossmann (2010). The results by Ahmetović et al. (2010) revealed that energy integration results in large reductions of water consumption by reducing the water losses by evaporation in the cooling tower. The superstructure consists of one or multiple sources of freshwater of different quality, waterusing processes, and wastewater treatment operations. The unique feature is that all feasible connections are considered between them, including water reuse, water regeneration, recycling, local recycling around process, and treatment units and pretreatment of feedwater streams. Multiple sources of freshwater include water of different quality that can be used in the various operations, and which may be sent first for pretreatment. The superstructure incorporates both the mass transfer and non-mass transfer operations.

From the integrated process design, wastewater streams are generated from the boiler, cooling tower, beer columns and discharge from condensations. Three main contaminants are considered: total suspended solids (TSS), total dissolved solids (TDS) and organics (BOD and COD). Suspended solids are present in the water used for washing the raw material, either grain or stover; the organics are the main contaminants in the streams coming out of the beer and rectification columns, condensation and mechanical press which dries the raw material, while the dissolved solids include the concentration of salts as a result of the evaporation processes in the boiler and the cooling tower. Furthermore, the water fed to the fermentors, either if it is syngas fermentation 
or sugar fermentation, must have no ethanol, which is toxic for the bacteria or yeast. We assume that there are three different wastewater treatment units, screens (TU1) that are capable of removing $99.9 \%$ of the suspended solids, a combined aerobic and anaerobic treatment that removes $100 \%$ of the organics (TU2) according to Zhan et al., (2009), and reverse osmosis (TU3) with a removal efficiency of 90\% (http://www.waterandwastewater.com) as well as the fact that fresh water has no contaminants at all. The models of the different units can be found in Ahmetović et al. (2010).

\section{4.- Results}

\section{1.-Energy and feedstock integration}

The integration of energy, technologies and feedstock for the production of ethanol from the entire plant of corn has a number of trade-offs that define the best integrated process. On the one hand, the integration of the corn grain with the thermo-biochemical path, in which the syngas generated by corn stover gasification is fermented towards ethanol, benefits from the use of the same technology for the dehydration of the ethanol which reduces the equipment cost. Furthermore, the total yield towards ethanol is higher in the thermo-biochemical path according to the results by Martín and Grossmann (2010). However, the low working temperature of the fermentors, $38^{\circ} \mathrm{C}$, does not allow good energy integration nor the recovery of energy from the exothermic reactions increasing the energy and the cooling needs resulting in higher freshwater consumption due to the losses at the cooling tower.

On the other hand, the integration of the corn grain process with the thermo-chemical path, where the syngas generated from the corn stover is converted into ethanol via mixed alcohols synthesis, provides good energy integration due to the reuse of the energy of the exothermic reaction to provide energy to other units such as distillation columns for the purification of ethanol and the treatment of the syngas. However, we run two processes in parallel with no synergy in the technologies, increasing the capital cost involved in the plant. Furthermore, the yield of the lignocellulosic material is lower (20\% vs $26 \%$ ) (Martín and Grossmann, 2010).

These trade-offs are resolved by the optimization of both processes using MIPSYN. Assuming that from the entire plant around $50 \%$ is grain and $50 \%$ is stover, and taking into account that out of the stover we can only remove $60 \%$ in order to keep the soil protected from erosion (Nielsen, 2009; Atchison and Hettenhaus, 
2003), the typical flow of $18 \mathrm{~kg} / \mathrm{s}$ of grain (Karuppiah et al., 2008) and $10.8 \mathrm{~kg} / \mathrm{s}$ of stover are used as a base case for the simulation. The superstructure model consists of about 26,500 variables and 25,000 constraints. We decompose the problem into two, one per alternative technology for processing the corn stover. Each subproblem consists of around 22,000 equations and 24,000 variables and can be solved in $8.2 \mathrm{~s}$ of CPU time using

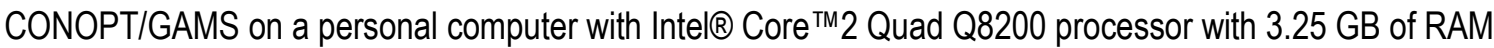

The results of the optimization are summarized in Table 1. The best integrated process, shown in Figure 6 , uses the thermo-chemical path for transforming the lignocellulosic material into ethanol (1.22 \$/gal vs. 1.35 \$/gal for thermo-biochemical path) especially due to the good energy integration in spite of the lower yield towards ethanol (0.28 kg Ethanol $/ \mathrm{kg}_{\text {biomass }} v \mathrm{vs.} 0.30 \mathrm{~kg}$ Ethanol $/ \mathrm{kg}_{\text {biomass }}$ for syngas fermentation)

Table 1. Summary of the integrated processes ( $18 \mathrm{~kg} / \mathrm{s}$ of grain and $10.8 \mathrm{~kg} / \mathrm{s}$ of stover)

\begin{tabular}{|c|c|c|c|c|c|c|}
\hline Process path & $\frac{\text { Steam }}{(\mathrm{MW})}$ & $\frac{\text { Electricity }}{(\mathrm{MW})}$ & $\frac{\text { Cooling }}{\text { (MW) }}$ & $\frac{\text { Cost }}{(\$ / \text { gal })}$ & $\frac{\text { Ethanol }}{\text { (Mgal/yr) }}$ & $\frac{\text { Profit }}{\text { (M\$/yr) }}$ \\
\hline Thermo-biochemical & 81 & -1.83 & 69 & 1.35 & 89.3 & 30 \\
\hline Thermo-chemical & 18 & 0.62 & 51 & 1.22 & 83.7 & 28 \\
\hline
\end{tabular}

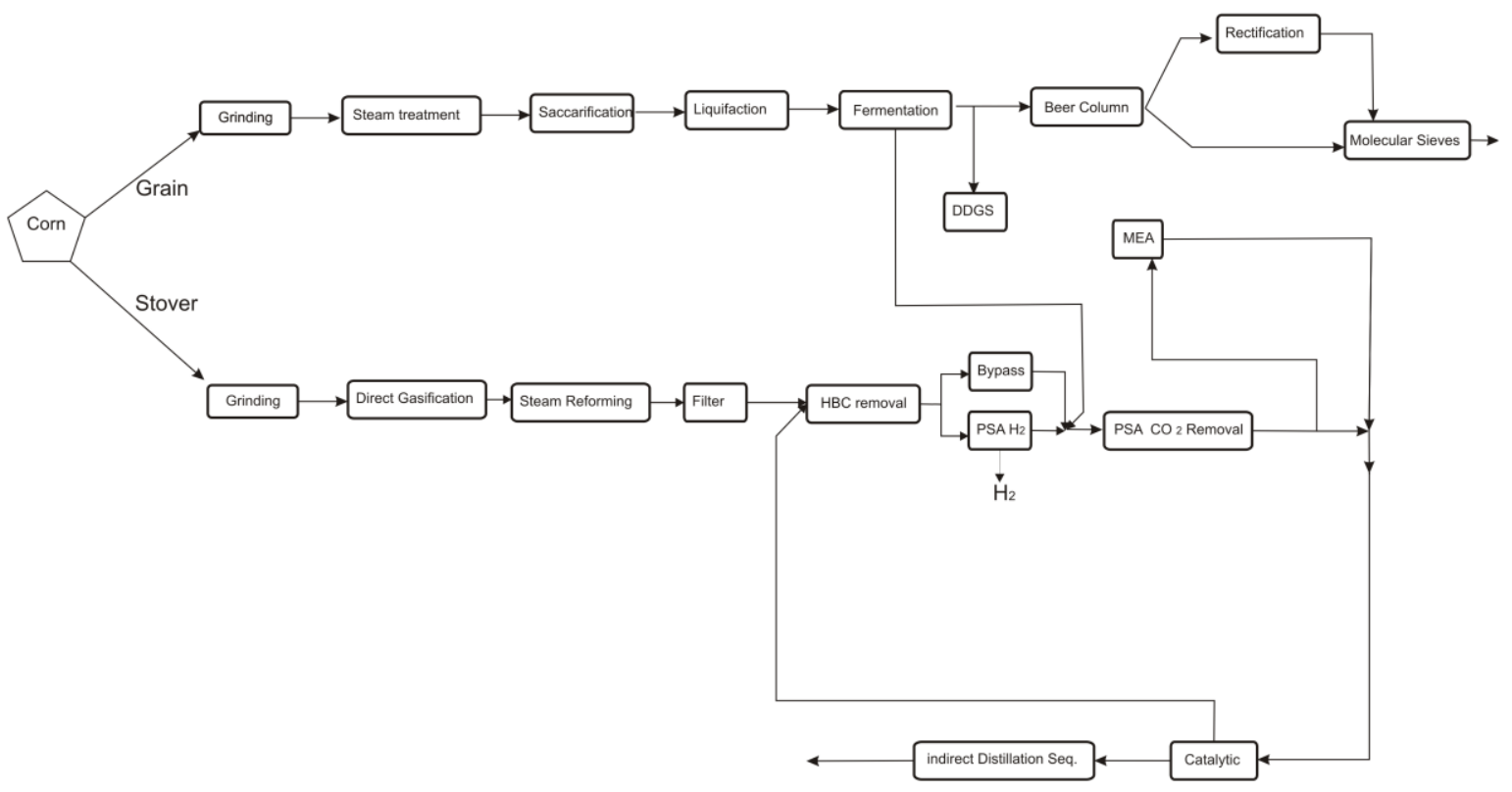

Figure 6.- Optimized integrated process for the entire corn crops-based ethanol. 


\section{2.-Water integration}

For the two integrated processes presented above we develop the optimal water network. The identification of the water consuming units is presented in Table 2.

Table 2.- Inventory of units for the water networks of the bioethanol processes.

\begin{tabular}{lll}
\hline \multicolumn{1}{c}{ Process Units } & \multicolumn{1}{c}{ Demand Units } & \multicolumn{1}{c}{ Source Units } \\
\hline P1: Washing Unit & D1: Fermentor/s & S1: Beer Column \\
P2: Boiler & D2: Boiler & S2: Rectifier Column \\
P3: Cooling Tower & D3: Cooling tower & S3: Condensation \\
\hline
\end{tabular}

Figure 7 shows the water network for the best integrated process, the integration of the dry-grind process and thermo-chemical path. For this process, the water consumption is 2 gal/gal before considering air cooling and the contribution of the simultaneous production of hydrogen. Those values are already in the order of the one used in the production of gasoline (Aden, 2007). Based on the results by Martín et al. (2010), this value can be reduced up to around $1.7 \mathrm{gal} / \mathrm{gal}$ when these two (or above mentioned) contributions are taking into account to reduce the use of cooling water as well as to discount the consumption of water due to the simultaneous production of hydrogen.

The integration of the thermo-biochemical process with the dry-grind process results in higher use of cooling utilities than in the case of the integration of the thermo-chemical process. The reason behind this is the fact that the fermentors operate at a very low temperature, $38^{\circ} \mathrm{C}$, which not only require the use of cooling water but also prevents from using this energy within the process. Thus, the consumption of freshwater in this integrated process turns out to be 2.3 gal/gal before considering the use of air cooling and the contribution of the hydrogen production, which can be reduced down to 1.9 gal/gal in case of considering both. In all cases, the consumption of freshwater is lower than the needed for the production of gasoline (Aden, 2007).

\section{3.-Effect of the feedstock on the integration}

In this section we increase the feed of lignocellulosic raw material. This can be interpreted as two different modes of operation of the biorefinery. On the one hand, lignocellulosic material can be provided from 
different sources such as switchgrass, wood wastes or residues from the forest industry. We assume that the composition of the added lignocellulosic material is the same as the corn stover. On the other hand, the increase in the ratio stover/grain can also be considered as the simultaneous production of food and ethanol by means of using the corn stover for ethanol production while the corn grain is used for both, food and ethanol. In this section we show the profile of the manufacturing cost, energy and cooling requirements for such process integration.

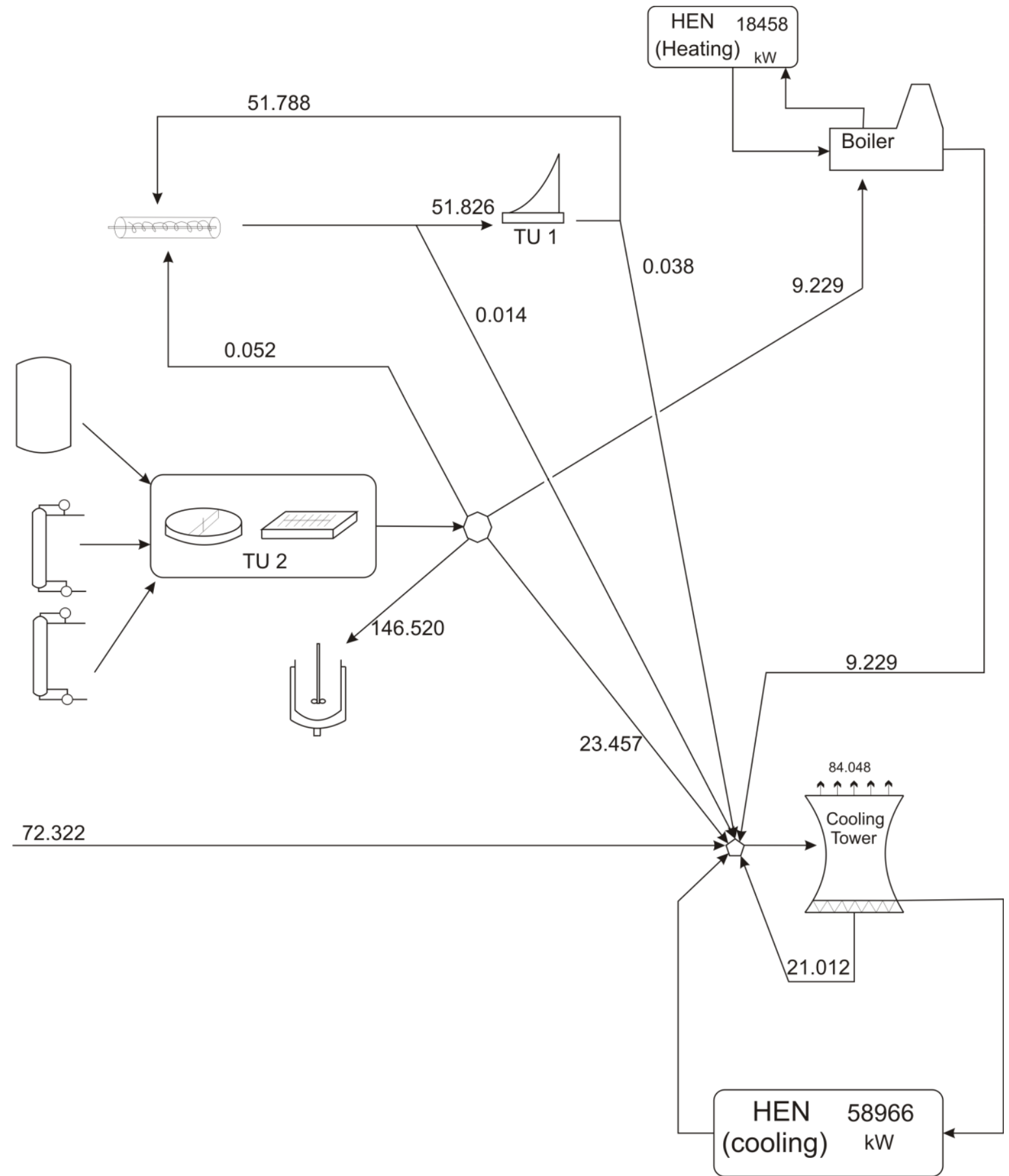

Figure 7.- Water network for the optimal integrated process (Flows in ton/h) TU1: Solids treatement; TU2: Organics treatment 
In Figure 8 we show the profile of the production cost as the ratio stover/grain increases from the base case, in which the entire corn plant is used for ethanol production. The manufacturing cost of the integrated process decreases as more lignocellulosic raw material is processed based on the fact that the excess of energy of the thermo-chemical or thermo-biochemical processes can be used in the dry-grind process, which is more energy intensive as well as the increase in the production of valuable byproducts such as hydrogen as well as due to the economies of the scale since the total production of ethanol increases. The extreme case, in which only lignocellulosic material is used according to Martín and Grossmann (2010), is the most profitable process to produce ethanol so long as its demand can be met with the harvested lignocellulosic raw material, while the use of grain is left for food production.

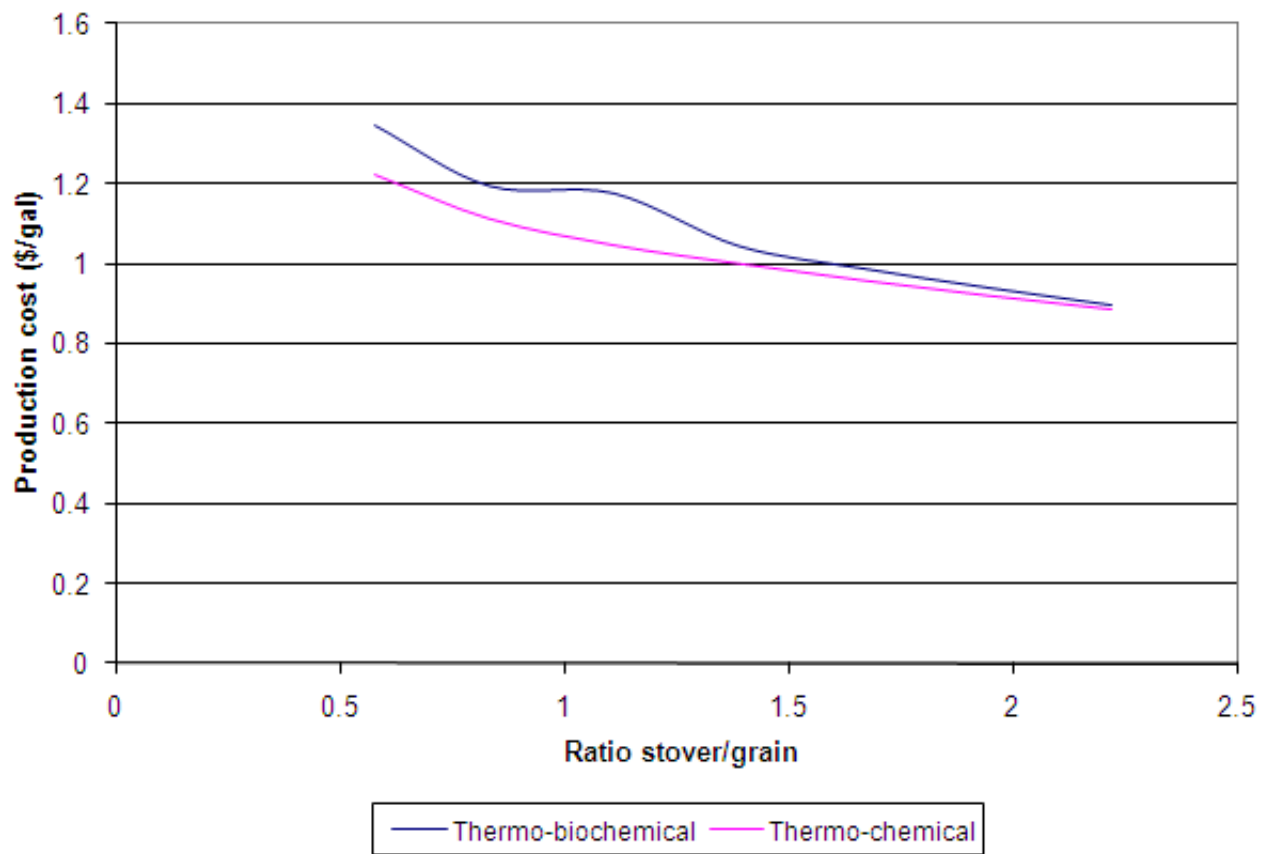

Figure 8. Effect of the ratio stover/grain on the manufacturing cost

Figures 9 and 10 show the cooling and net energy needs of the integrated process as more lignocellulosic material is processed. In the case of the integration of the grain based process with the thermochemical one, for a ratio of the two feedstocks equal to 1, almost no energy is needed and the cooling requirements start to increase. Under these conditions $43 \%$ of the grain is used for food, while $57 \%$ is used for ethanol production together with all the corn stover. For stover/grain ratios larger than 1 the pinch location method implemented in MIPSYN (Duran and Grossmann, 1986) indicates an excess of energy that has to be removed from the process. Part of that excess of energy may be used to produce steam that will help in the economics of 
the process reducing the production cost, however this option is not included in the cost analysis to be on the conservative side in terms of production cost.

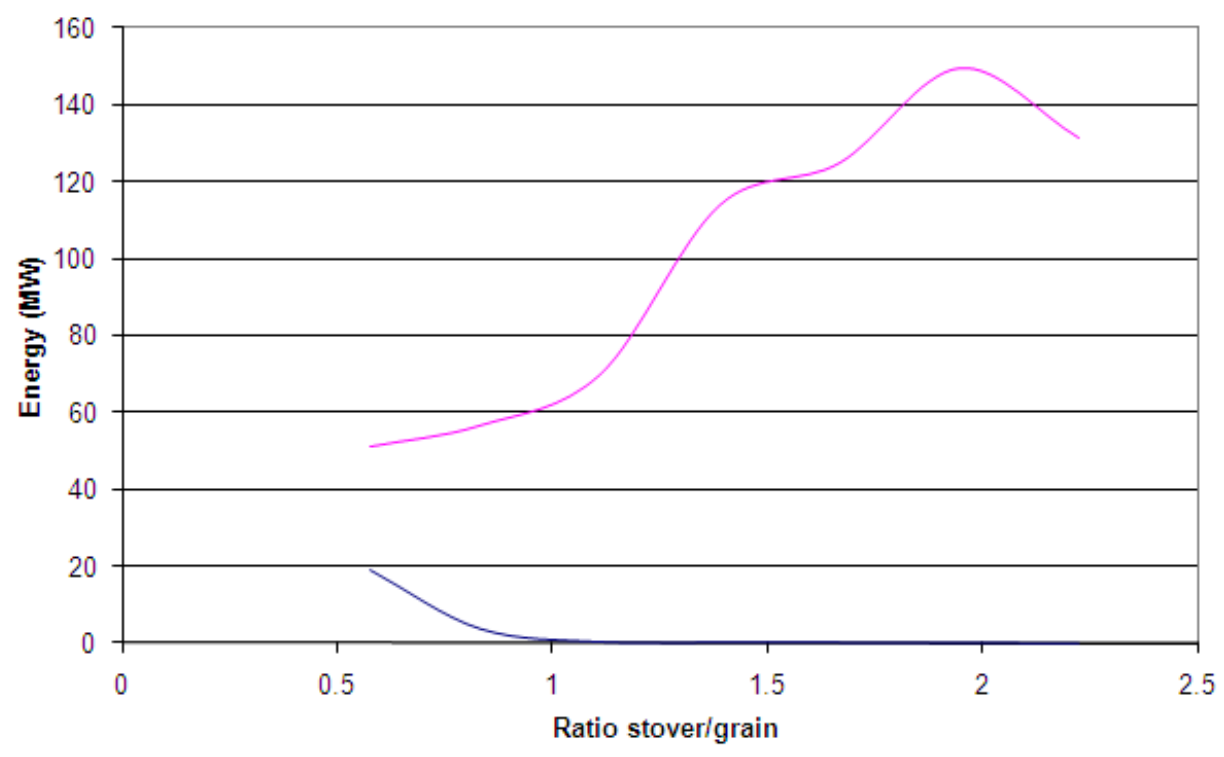

- Total Energy (MW) Cooling (MW)

Figure 9. Thermo-chemical process integration. Effect of ratio stover to grain

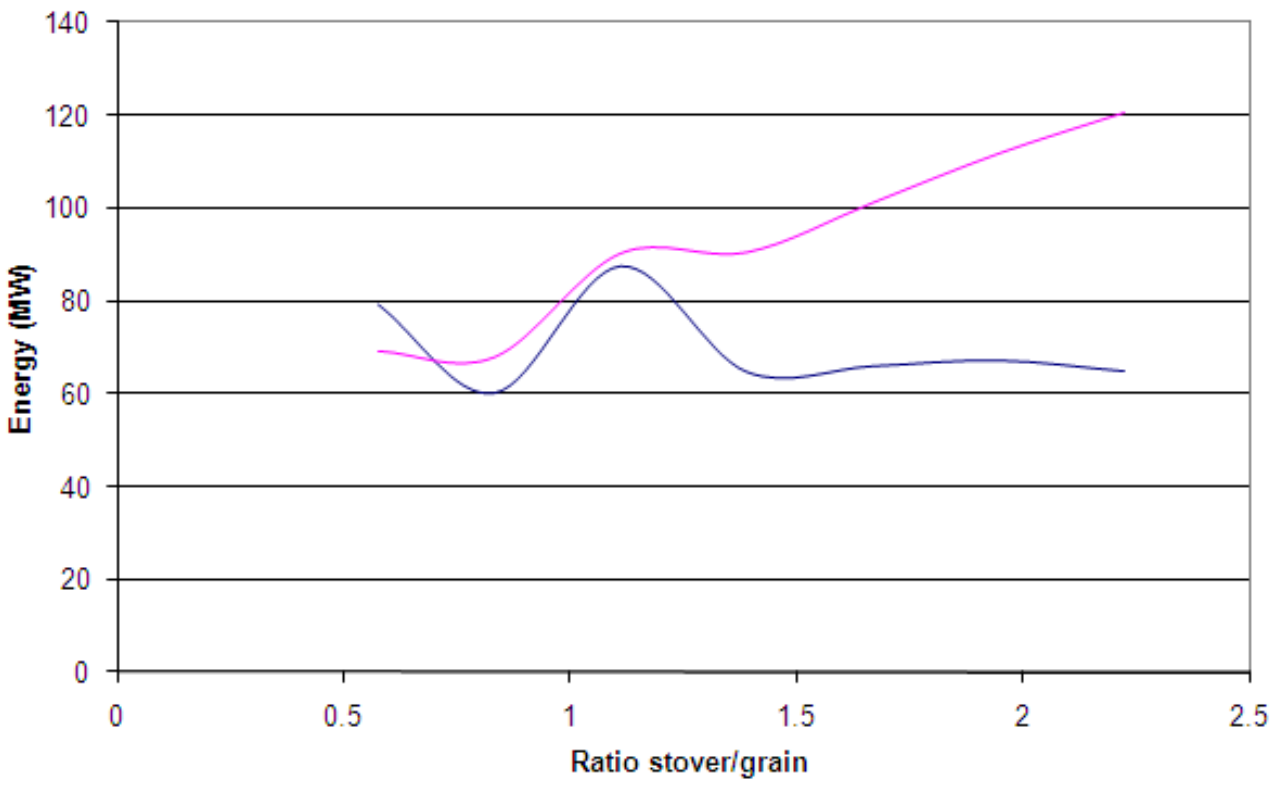

- Total energy (MW) - Total Cooling (MW)

Figure 10. Thermo-biochemical process integration. Effect of ratio stover to grain

In the case of the integration of the grain-based process with the thermo-biochemical process, the excess of energy of the thermo-biochemical process can be used for low production of ethanol using the thermal route. However, as the use of stover increases, the presence of the glucose and syngas fermentors operating at low temperature limits the energy integration resulting in an increase of the energy required as can be seen in 
figure 10. When the use of corn stover overtakes that of grain, the excess of energy from this path allows better integration, but it is still limited by the low temperature operation of the reactors and the high energy demand in the dehydration part of the process. Unlike the case of the integration of the dry-grind with the thermo-chemical route, this integrated process consumes energy and even though cooling is required most of the energy comes from the fermentation reactors and cannot be reused since the operate at $38^{\circ} \mathrm{C}$.

As the ratio stover vs. grain increases (see Figure 11) the yield towards ethanol decreases based on the lower yield of the thermo based paths compared to the dry-grind process. This decrease is quicker in the case of the thermo-chemical path due also to the lower yield compared to the thermo-biochemical one as presented by Martín and Grossmann (2010).

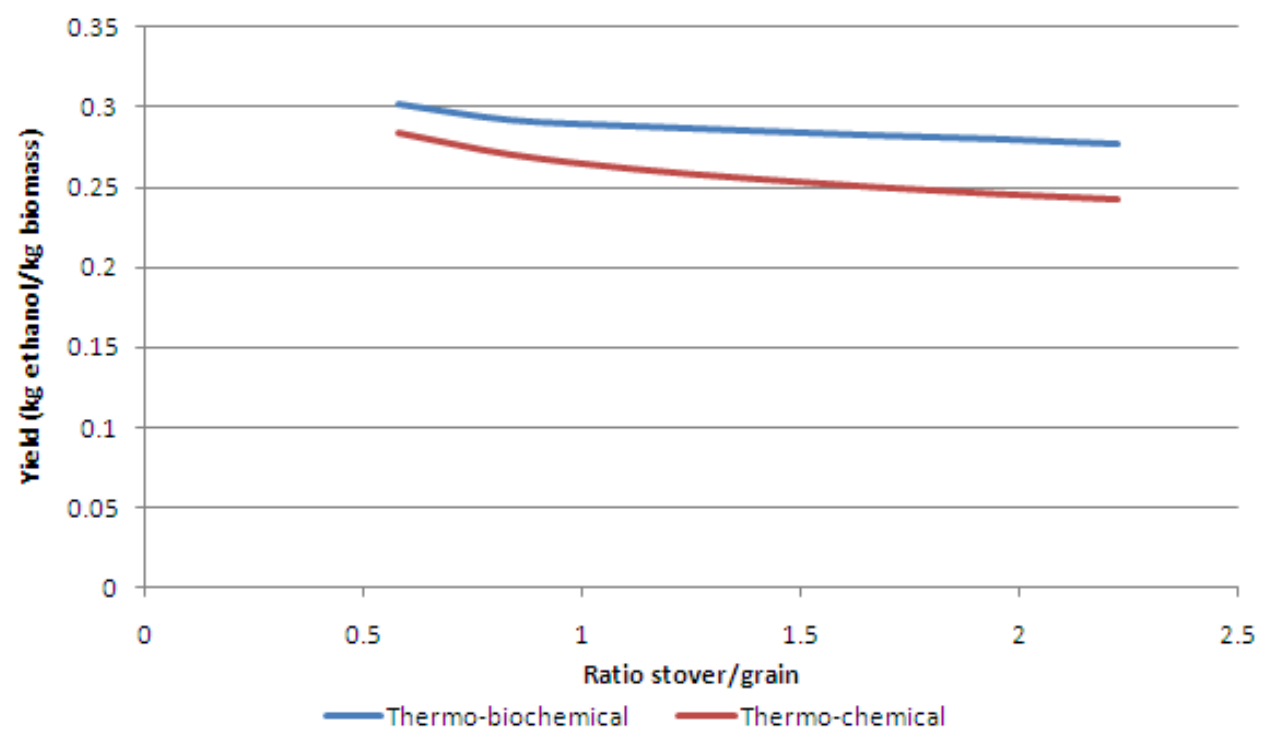

Figure 11.- Effect of the ratio stover vs. grain in the total yield towards ethanol

Finally, Figure 12 shows the profiles of the consumption of corn stover and/or grain for a given fixed amount of entire corn plant available vs. variable ethanol production using the thermo-chemical route as the path to produce ethanol from the corn stover and the dry grind process for processing the corn grain. So far the maximum production of ethanol from biomass has been limited to the amount of biomass available within a distance of the production plant. Typically the production capacity of such biorefineries is $60 \mathrm{Mgal} / \mathrm{yr}$ consuming $30 \mathrm{~kg} / \mathrm{s}$ of lignocellulosic biomass (based on the yield of the process, Martín and Grossmann, 2010). We assume that this is the maximum availability of corn stover and, according to the results by Atchison and Hettenhaus 
(2003) and Nielsen (2009), together with this production of stover up to $50 \mathrm{~kg} / \mathrm{s}$ of grain is produced. As it can be seen in Figure 12, the optimal process for meeting the demand of ethanol consists of using the lignocellulosic raw material as long as it is available and only beyond that the grain is used for the production of ethanol instead of food.

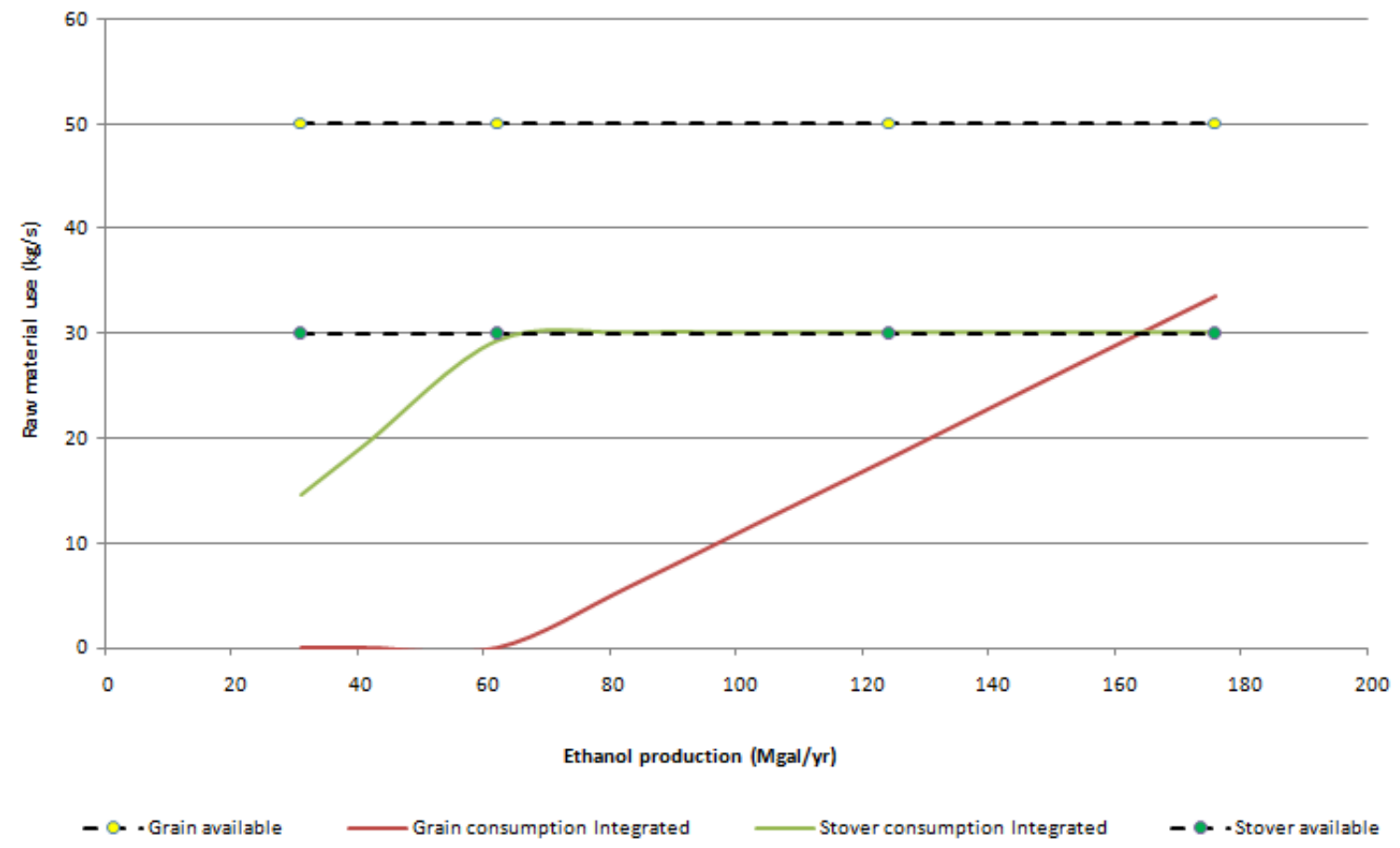

Figure 12.-Distribution of raw material consumption for a fixed production of ethanol

In order to complement these results, Figure 13 shows the effect of the economy of scale, presenting the production cost of ethanol for the individual processes, based on the results by Karuppiah et al. 2008 (updating the cost) and Martín and Grossmann (2010), and the integrated processes presented in this paper. For a maximum availability of $30 \mathrm{~kg} / \mathrm{s}$ of stover and $50 \mathrm{~kg} / \mathrm{s}$ of grain, the optimal production is $60 \mathrm{Mgal} / \mathrm{yr}$ based on the use of stover for ethanol while the grain is used for food, as recommended by Figure 12. If the demand of ethanol is higher, we can still produce more ethanol by using grain and stover at a higher cost looking for good energy integration between the processes. In this case, the best integrated process consists of using the thermochemical path for processing the stover and the dry-grind for the grain due to the better energy integration between both. From Figure 9 it can be seen that the best integration occurs when the ratio stover/grain is approximately 1 . This is the case when the excess of energy from the thermo-chemical process is used for 
biochemical production of ethanol from corn, with approximate production cost of $\$ 1 /$ gal. Finally, the maximum production of ethanol from the entire harvested biomass could reach around $225 \mathrm{Mgal} / \mathrm{yr}$.

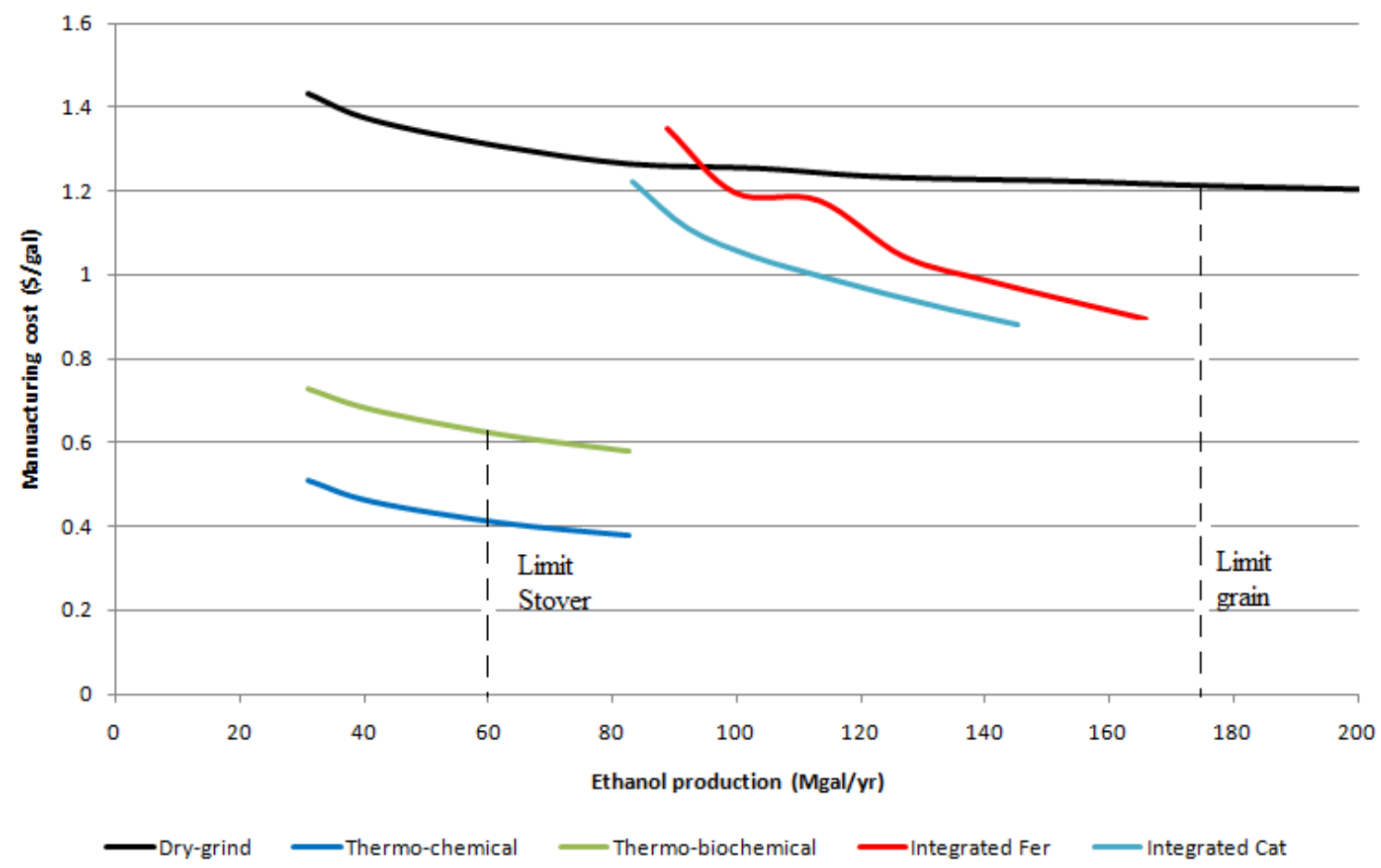

Figure 13.- Effect of the economy of scale

\section{5.-Conclusions}

In this paper we have studied the simultaneous integration of technologies, feedstock and energy towards the sustainable production of ethanol from corn in the form of grain and stover. The process was modeled with the process synthesizer MIPSYN, consisting of mass and energy balances, design constraints and short-cut equations. The use of mathematical optimization techniques implemented in the MIPSYN proved to be a powerful tool for analyzing the large number of trade-offs of this case study.

It was found that the most economical process is based on thermo-chemical route while the most economical integrated process consists of the thermo-chemical route and dry-grind process due to the large impact of the heat integration that can be achieved. The availability of energy at high temperature at the reactor is useful to reduce the energy consumption of the beer column for the dehydration of the ethanol. While in the short term the production of ethanol from grain and stover will co-exist, the lignocellulosic material will eventually displace the use of grain due to its lower cost. 
Despite the need for a more detailed analysis and pilot plant experiments to verify the results of the proposed integrated process, these results are promising as a bridge between both generations of bioethanol.

\section{Ackowledgements}

The authors acknowledge the Slovenia-USA bilateral project. Prof. Kravanja and Eng. Čuček are grateful to the Slovenian Research Agency for its financial support (Program P2-0032, Project L2-0358, PhD research fellowship contract No. 1000-08-310074). Prof. Grossmann and Dr. Martín acknowledge NSF Grant CBET0966524 and Dr. M. Martín also acknowledges the financial support from the Ministry of Education and Science of Spain and Fulbright commission providing a MICINN - Fulbright Postdoctoral fellowship.

\section{References}

Aden, A. (2007) Water usage for current and future ethanol production September/October $2007 \cdot$ Southwest Hydrology, 22-23

Ahmetović, E., and Grossmann, I. E. (2010) General superstructure and global optimization for the design of integrated process water networks, AIChE J., DOI: 10.1002/aic.12276

Ahmetović, E., Martín, M., and Grossmann, I. E. (2010) Optimization of Energy and Water Consumption in Cornbased Ethanol Plants, Ind. Eng. Chem. Res., 49 (17), 7972-7982

Atchison, J., and Hettenhaus, J. (2003) Innovative methods for corn stover collecting, handling, storage, and transporting. Report No ACO-1-31042-01, National Renewable Energy Laboratory, Golden, CO

Bozell, J. J., and Landucci, R. (1993) Technical and economic assessment: thermal/chemical and bioprocessing components. Report to the Alternative Feedstocks Program, National Renewable Energy Laboratory, Golden, CO

Cardona, C. A., and Sánchez, O. J. (2006) Energy consumption analysis of integrated flowsheets for production of fuel ethanol from lignocellulosic biomass, Energy, 31, 2447- 2459

Cole, D. E. (2007) Issues facing the Auto Industry: Alternative Fuels, Technologies, and Policies, ACP Meeting Eagle Crest Conference Center, June 20, 2007

DiPardo, J. (2000) Outlook for biomass ethanol production and demand, Energy Information Administration (EIA), Washington, DC

Duran, M.A., and Grossmann, I.E. (1986) Simultaneous Optimization and Heat Integration of Chemical Processes, AlChE J., 32, 123 -138

Elcock, D. (2008) Baseline and Projected Water Demand Data for Energy and Competing Water Use Sectors, ANL/EVS/TM/08-8, http://www.evs.anl.gov/pub/dsp_detail.cfm?PubID=2322 (Last accessed: September 2010)

Ferguson, A. R. B. (2003) Implications of the USDA 2002 update on ethanol from corn: The Optimum Population Trust, Manchester, U.K., 11-15

Ferguson, A. R. B. (2004) Further implications concerning ethanol from corn: Draft manuscript for the Optimum Population Trust

Hamelinck, C. N., Geertje van Hooijdonk, G., and Faaij, A.P.C. (2005) Ethanol from lignocellulosic biomass: techno-economic performance in short-, middle- and long-term, Biomass and Bioenergy, 28, 384-410 
Huhnke, R. L. (2008) Cellulosic ethanol using gasification-fermentation, Resource: Engineering \& Technology for a Sustainable World, http://www.articlearchives.com/energy-utilities/renewable-energy-biomass/896186-1.html (Last accessed: August 2009)

lowa Department of Natural Resources (2000) Biomass, Energy Bureau, lowa Department of Natural Resources, Des Moines, IA

Jablonski, W., Gaston, K. R., Nimlos, M. R., Carpenter, D. L., Feik, C. J., and Phillips, S.D. (2009) Pilot-Scale Gasification of Corn Stover, Switchgrass, Wheat Straw, and Wood: 2. Identification of Global Chemistry Using Multivariate Curve Resolution Techniques, Ind. Eng. Chem. Res., 48, 10691-10701

Jacques, K., Lyons, T. P., and Kelsall, D. R. (1999) The Alcohol Textbook, 3rd ed. Nottingham, United Kingdom: Nottingham University Press

Karuppiah, R., Peschel, A., Grossmann, I. E., Martín, M., Martinson, W., and Zullo, L. (2008) Energy optimization of an Ethanol Plant, AIChE J., 54, 1499-1525

Keshwani, D. R., Cheng, J. J. (2009) Switchgrass for bioethanol and other value-added applications: A review. Bioresour. Technol., 100, 1515-1523

Kocis, G. R., and Grossmann, I. E. (1987) Relaxation Strategy for the Structural Optimization of Process Flowsheets. Ind. Eng. Chem. Res., 26, 1869-1880

Kocis, G. R., and Grossmann, I. E. (1989) A Modelling and Decomposition Strategy for the MINLP Optimization of Process Flowsheets. Comp. Chem. Eng., 13, 797-819

Kravanja, Z. (2010) Challenges in Sustainable Integrated Process Synthesis and the Capabilities of an MINLP Process Synthesizer MipSyn, Comp. Chem. Eng., DOl: 10.1016/j.compchemeng.2010.04.017

Kravanja, Z., and Grossmann, I. E. (1990) PROSYN - an MINLP Process Synthesizer, Comp. Chem. Eng., 14 (12), 1363-1378

Kravanja, Z., and Grossmann, I. E. (1994) New developments and capabilities in Prosyn: an automated topology and parameter process synthesizer, Comp. Chem. Eng., 18, 1097-1114

Martín, M., and Grossmann, I. E. (2010) Energy Optimization of Bioethanol Production via Gasification of Switchgrass, to be submitted AIChE $J$.

Martín, M., Ahmetović, E., and Grossmann, I. E. (2010) Optimization of Water Consumption in Second Generation Bioethanol Plants, accepted to Ind. Eng. Chem. Res.

Nielsen (2009) http://www.agry.purdue.edu/ext/corn/pubs/agry9509.htm (Last accessed: May 2010)

Phillips, S., Aden, A., Jechura, J. and Dayton, D., and Eggeman, T (2007) Thermochemical Ethanol via Indirect Gasification and Mixed Alcohol Synthesis of Lignocellulosic Biomass, Technical Report, NREL/TP-510-41168, April 2007

Piccolo, C., and Bezzo, F. (2009) A techno-economic comparison between two technologies for bioethanol production from lignocelluloses, Biomass Bioener., 33, $478-491$

Pimentel, D. (1998) Energy and dollar costs of ethanol production with corn: Hubbert Center Newsletter \#98/2, M. King Hubbert Center for Petroleum Supply Studies, Colorado Sch. Mines.Golden, CO. 7 p.

Pimentel, D. (2001) The limitations of biomass energy, in Meyers, R., ed., Encyclopedia of Physical Science and Technology (3rd edn.), Vol. 2: Academic, San Diego, CA, 159-171 
Pimentel, D. (2003) Ethanol fuels: energy balance, economics, and environmental impacts are negative: Nat. Resour. Res., 12, 2, 127-134

Shapouri H., et al. (1995) Estimating the net energy balance of corn ethanol. In U.S. Department of Agriculture (USDA), Economic Research Service, Agricultural Economic Report No 721

Shapouri, H., Duffield, J. A., and Wang, M. (2002) The energy balance of corn ethanol: an update: USDA, Office of Energy Policy and New Uses, Agricultural Economics, Rept. No 813, 14 p.

Shapouri, H., Duffield, J., McAloon, A., and Wang, M. (2004) The 2001 Net Energy Balance of Corn-Ethanol (Preliminary): US Dept. Agriculture, Washington, DC

Walsh, M. E., Perlack, R. L., Turhollow, A., de la Torre Ugarte, D., Becker, D. A., Graham, R. L., Slinsky, S. E., and Ray, D. E. (2000) Biomass feedstock availability in the United States: 1999 state level analysis. Oak Ridge National Laboratory, Oak Ridge, TN

Water and Wastewater (2010)

http://www.waterandwastewater.com/cgibin/yabb/YaBB.pl?board)general;action)display;num)1190280253 (Last accessed March 10, 2010)

Zhang, S., Marechal, F., Gassner, M., Perin-Levasseur, Z., Qi, W., Ren, Z., Yan, Y., and Favrat, D. (2009) Process Modeling and Integration of Fuel Ethanol Production from Lignocellulosic Biomass Based on Double Acid Hydrolysis. Energy Fuels, 23 (3), 1759-1765

Zhu, Y., Gerber, M. A., Jones, S. B., and Stevens, D. J. (2009) Analysis of the effects of compositional and configurational assumptions on product costs for the thermochemical conversion of lignocellulosic biomass to mixed alcohols. FY 2007 Progress report, DOE PNNL.17949 Revision 1 
Table 1. Summary of the integrated processes ( $18 \mathrm{~kg} / \mathrm{s}$ of grain and $10.8 \mathrm{~kg} / \mathrm{s}$ of stover)

\begin{tabular}{|c|c|c|c|c|c|c|}
\hline Process path & $\frac{\text { Steam }}{(\mathrm{MW})}$ & $\frac{\text { Electricity }}{(\mathrm{MW})}$ & $\frac{\text { Cooling }}{\text { (MW) }}$ & $\frac{\text { Cost }}{(\$ / \text { gal })}$ & $\frac{\text { Ethanol }}{\text { (Mgal/yr) }}$ & $\frac{\text { Profit }}{\text { (M\$/yr) }}$ \\
\hline Thermo-biochemical & 81 & -1.83 & 69 & 1.35 & 89.3 & 30 \\
\hline Thermo-chemical & 18 & 0.62 & 51 & 1.22 & 83.7 & 28 \\
\hline
\end{tabular}


Table(s)

Table 2.- Inventory of units for the water networks of the bioethanol processes.

\begin{tabular}{lll}
\hline \multicolumn{1}{c}{ Process Units } & \multicolumn{1}{c}{ Demand Units } & \multicolumn{1}{c}{ Source Units } \\
\hline P1: Washing Unit & D1: Fermentor/s & S1: Beer Column \\
P2: Boiler & D2: Boiler & S2: Rectifier Column \\
P3: Cooling Tower & D3: Cooling tower & S3: Condensation \\
\hline
\end{tabular}


Click here to download high resolution image

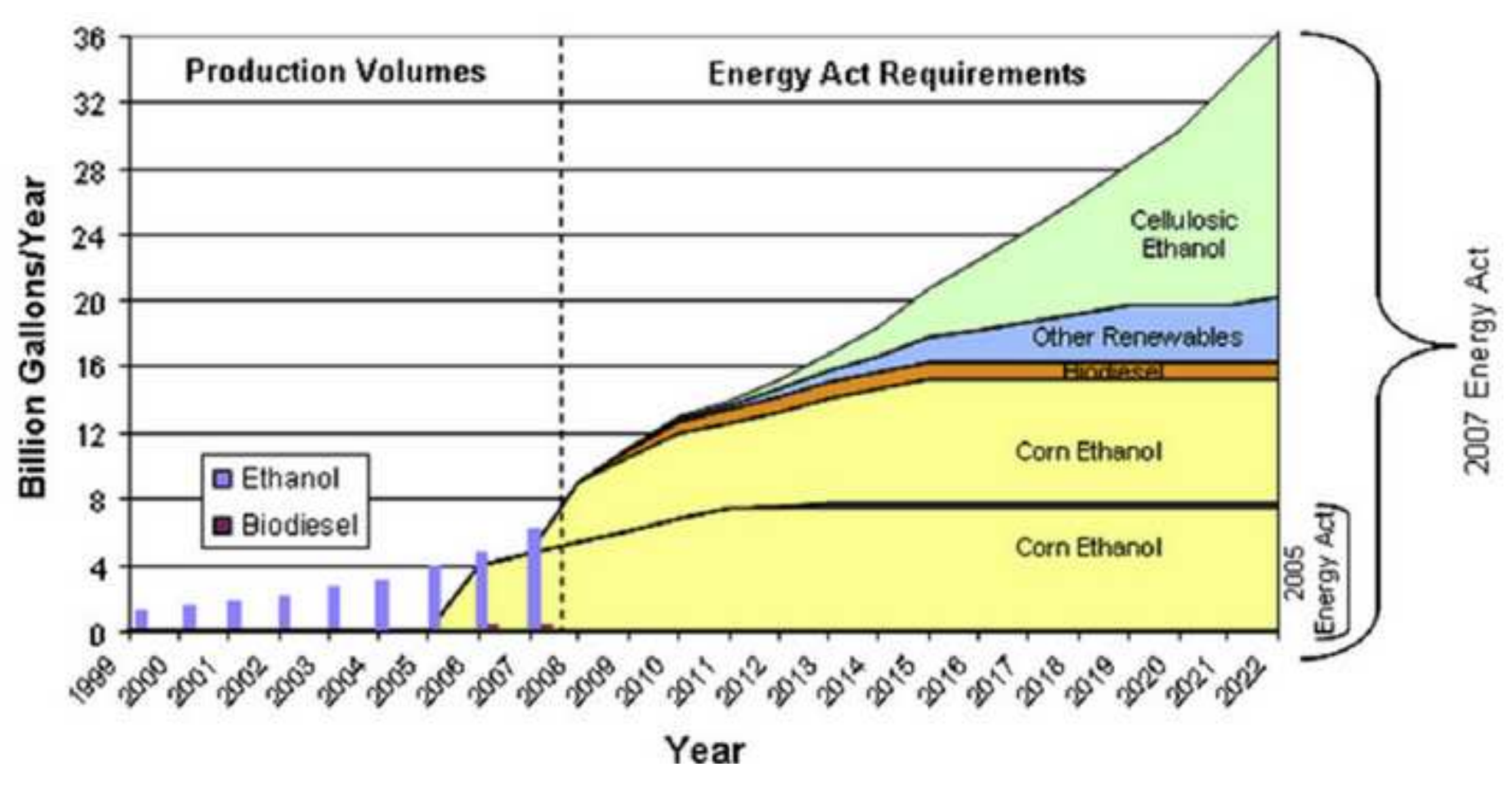




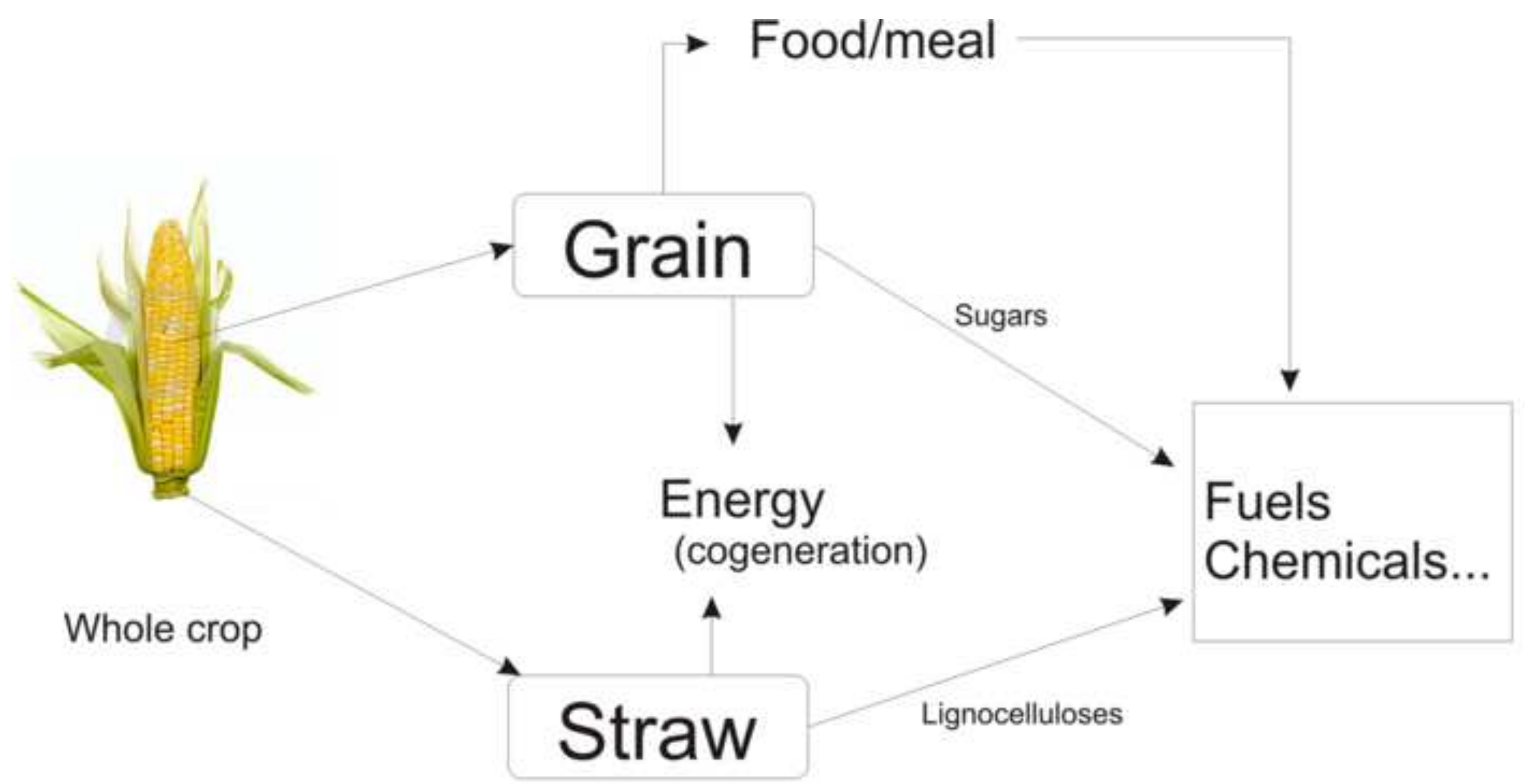




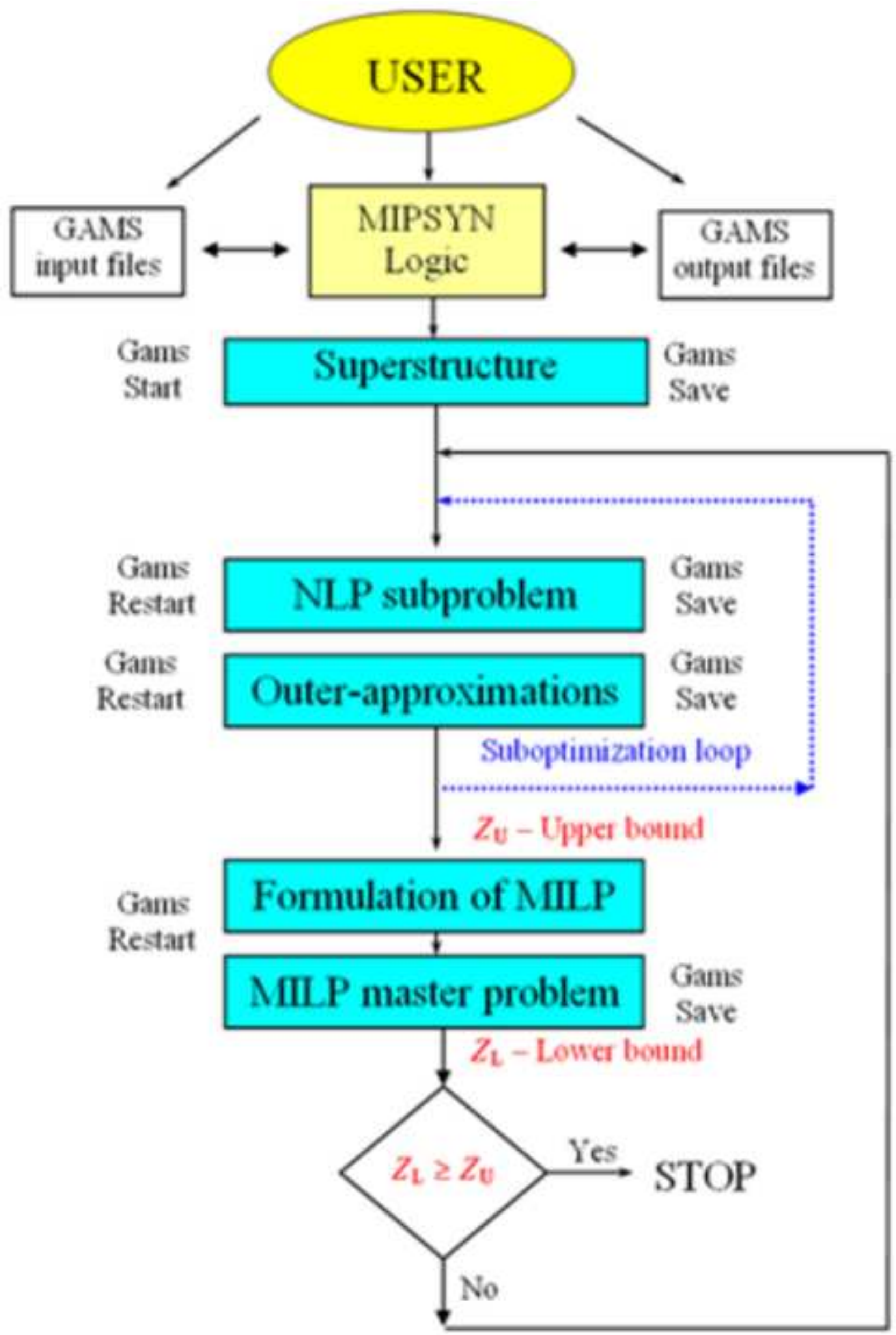




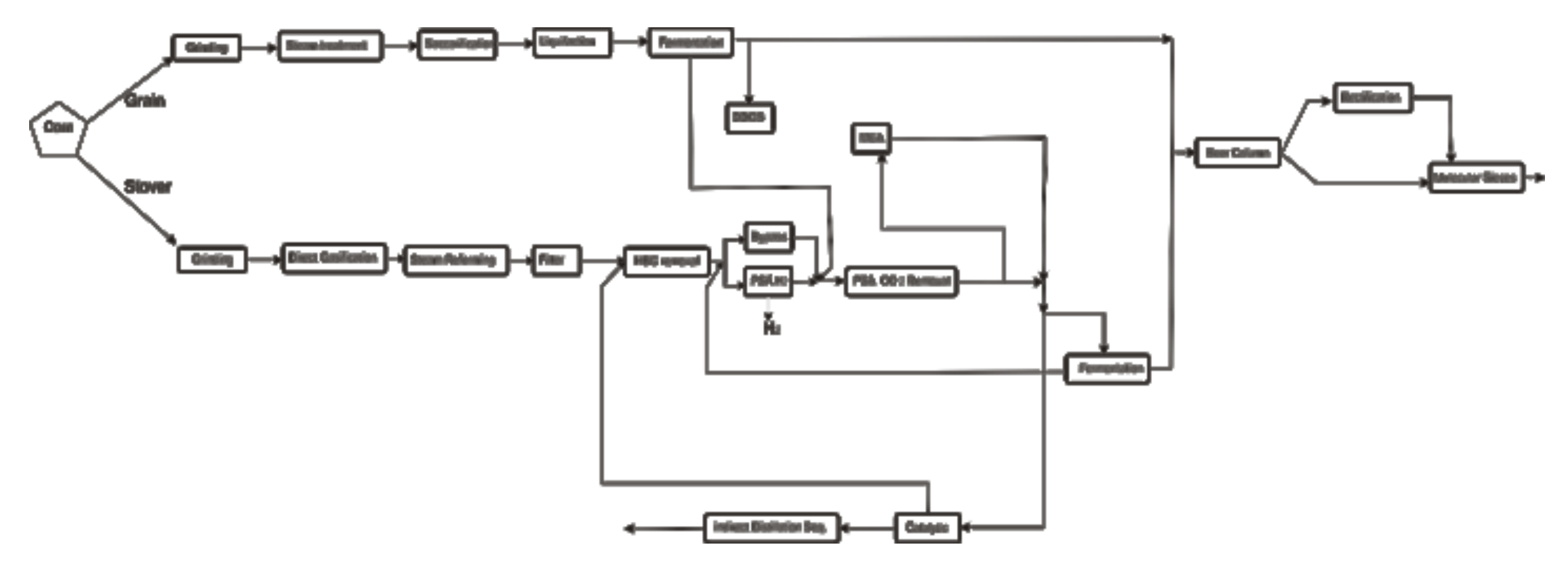




\section{Gas and}

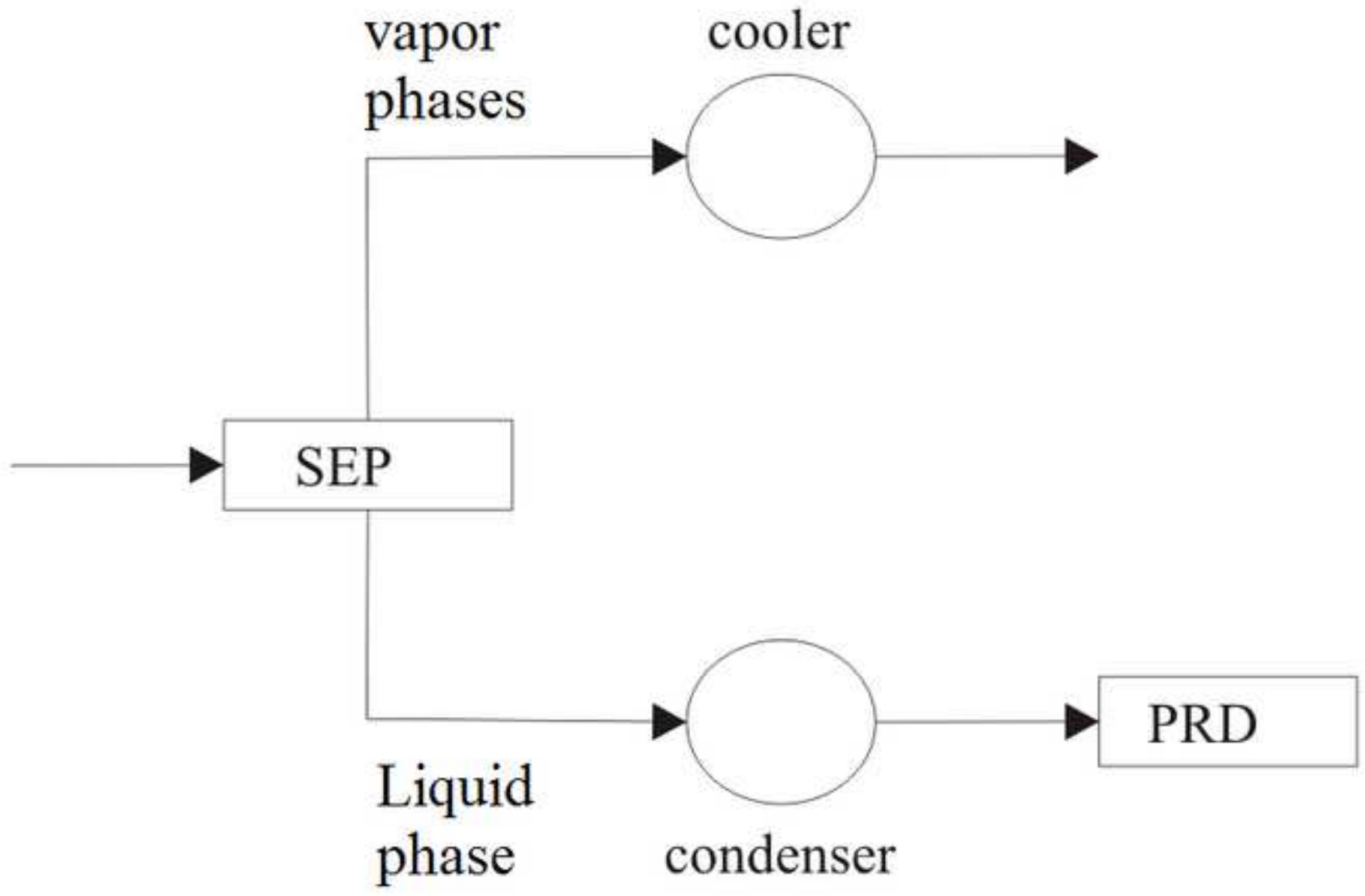




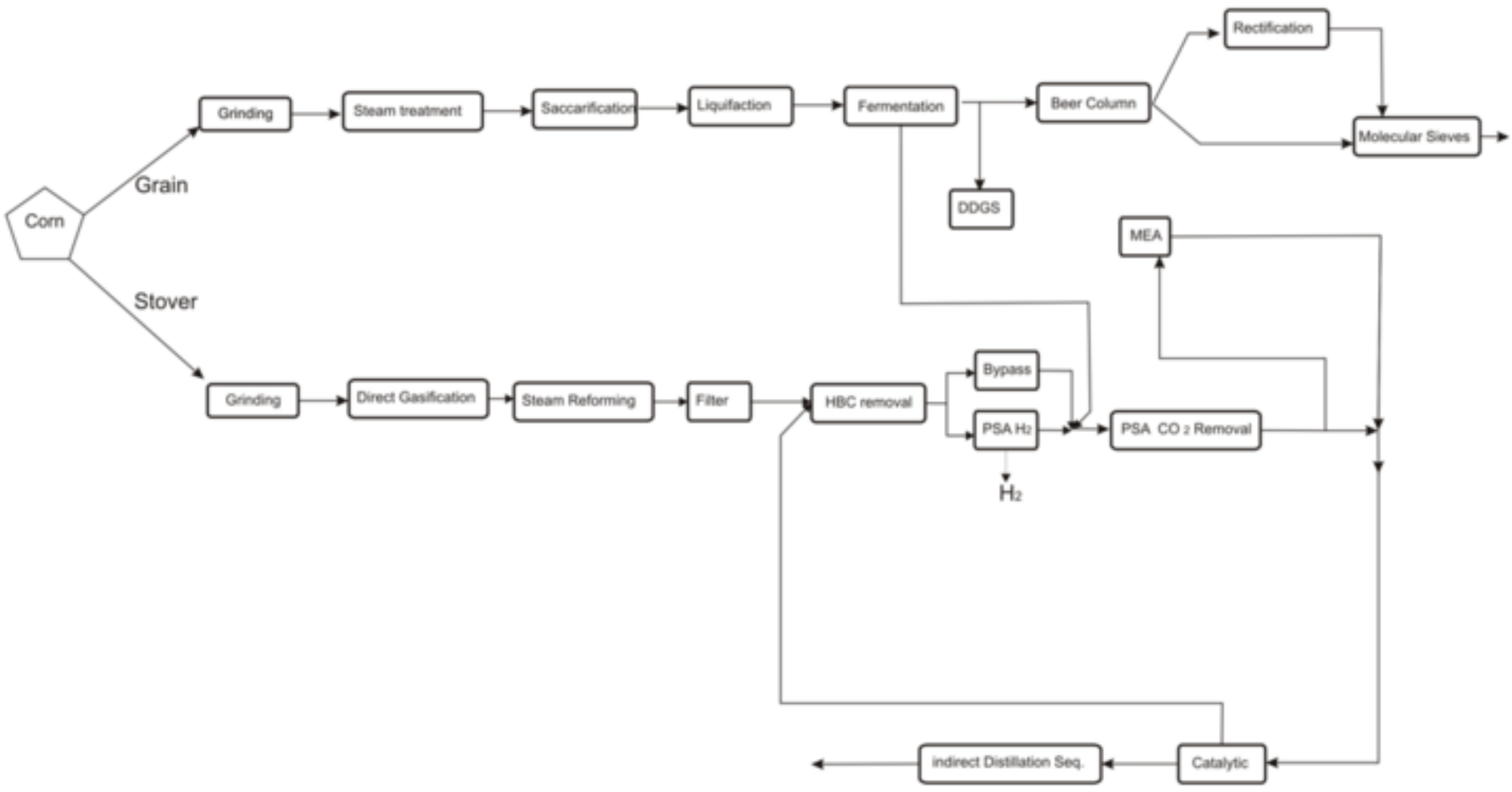




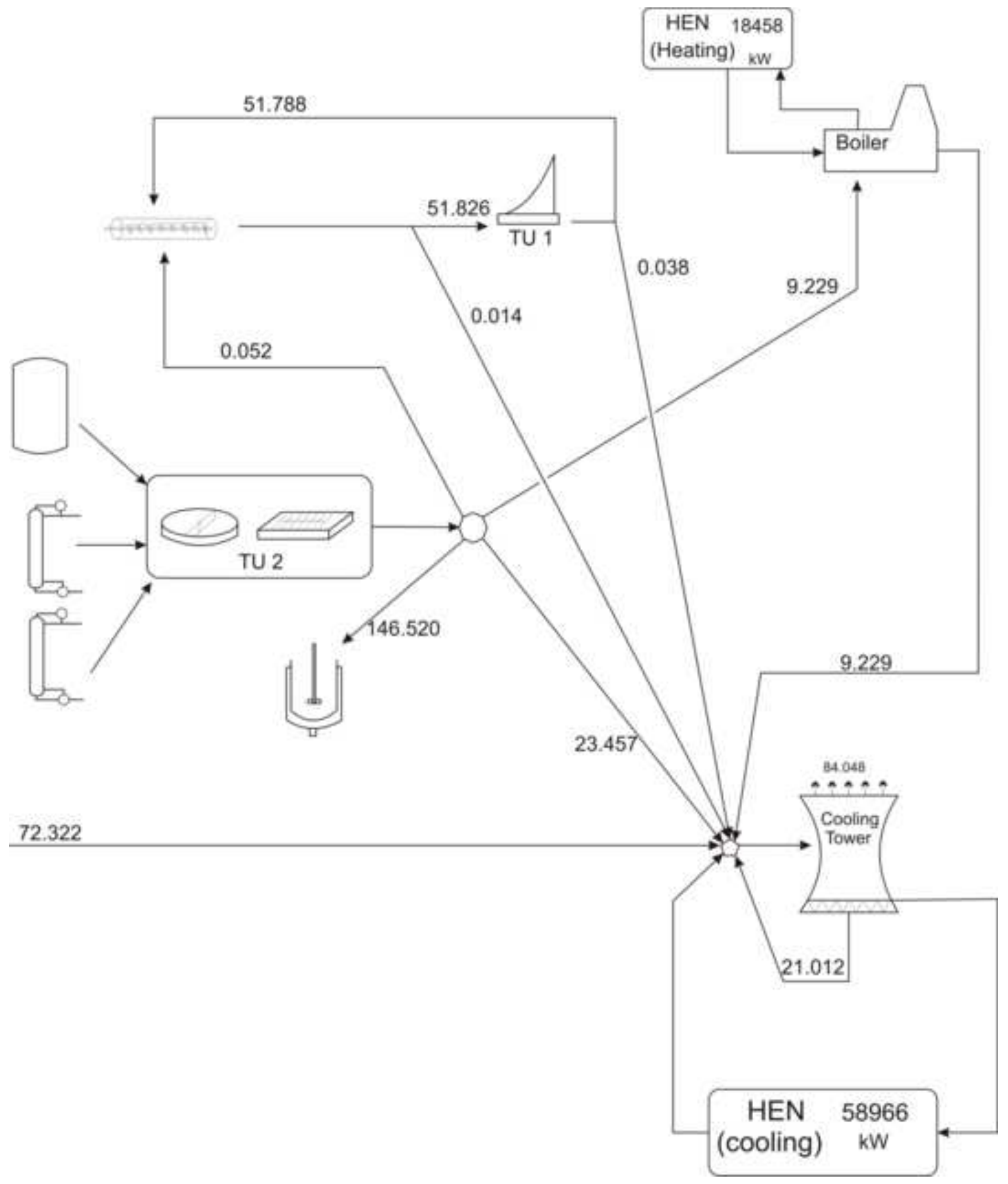


Click here to download high resolution image

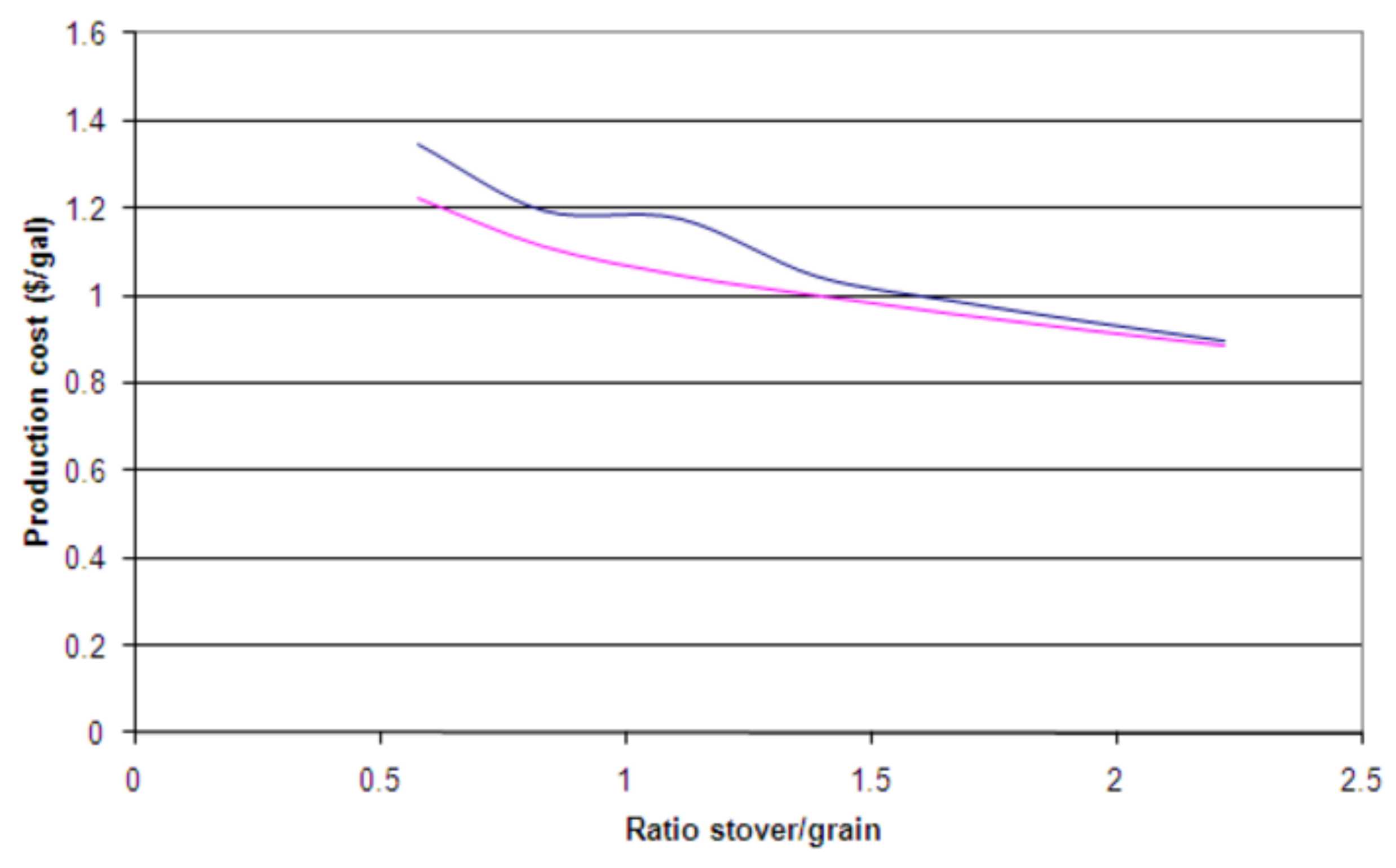

- Thermo-biochemical - Thermo-chemical

Clck here to download high resolution image 
Click here to download high resolution image

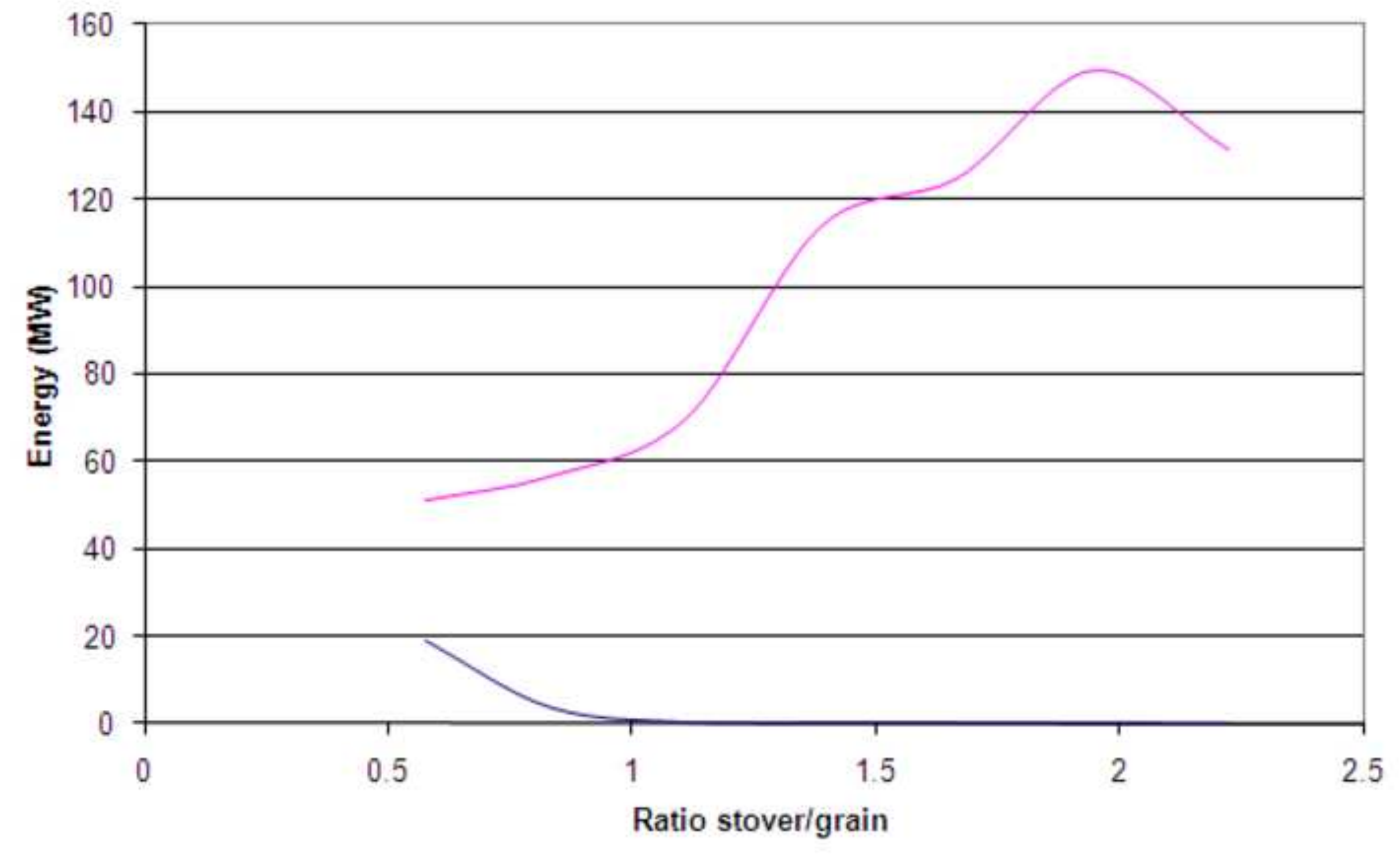

- Total Energy $(\mathrm{MW})-$ Cooling $(\mathrm{MW})$

- Total Energy (MW) - Cooling (MW) 
Click here to download high resolution image

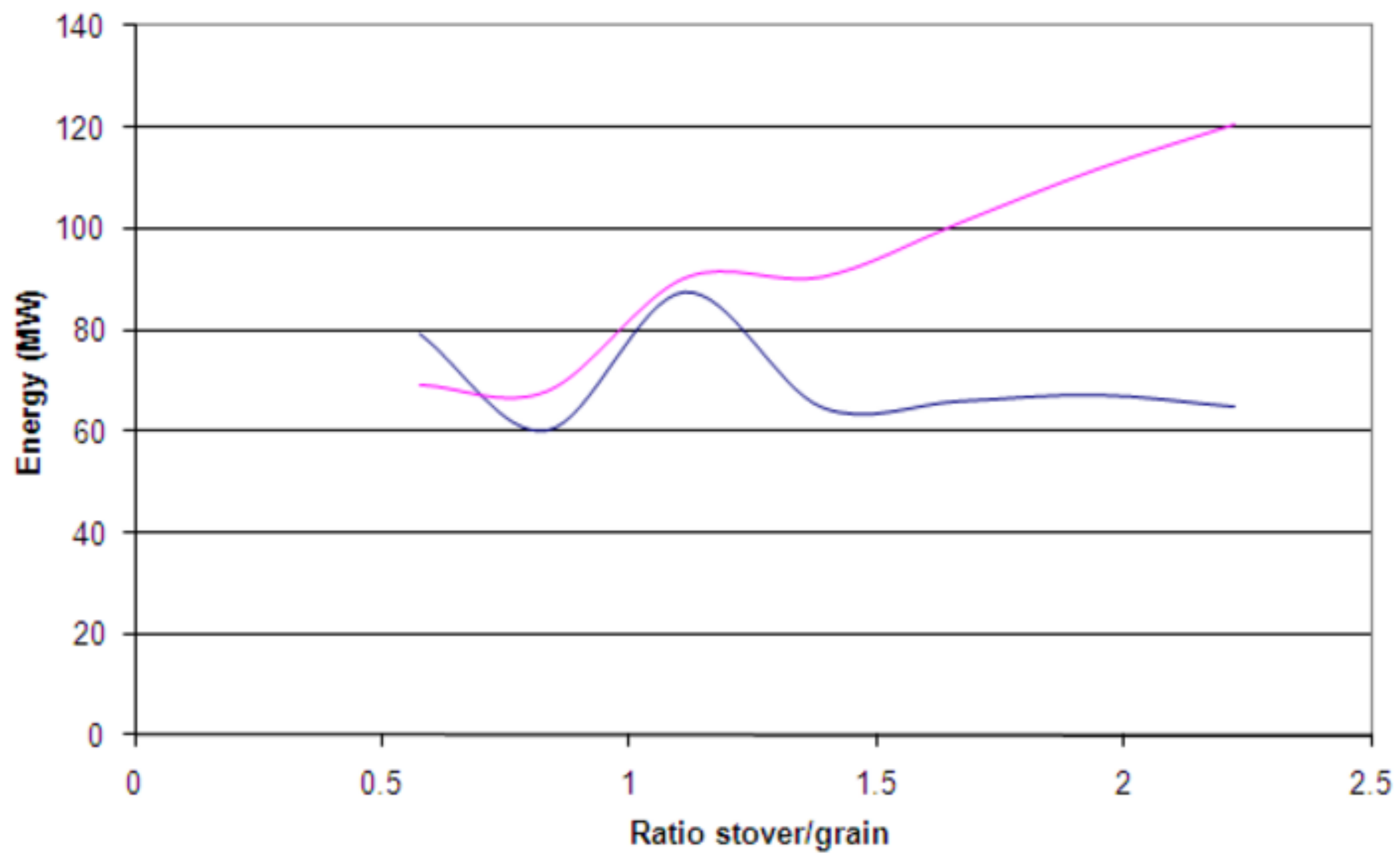

- Total energy (MW) - Total Cooling (MW)


Click here to download high resolution image

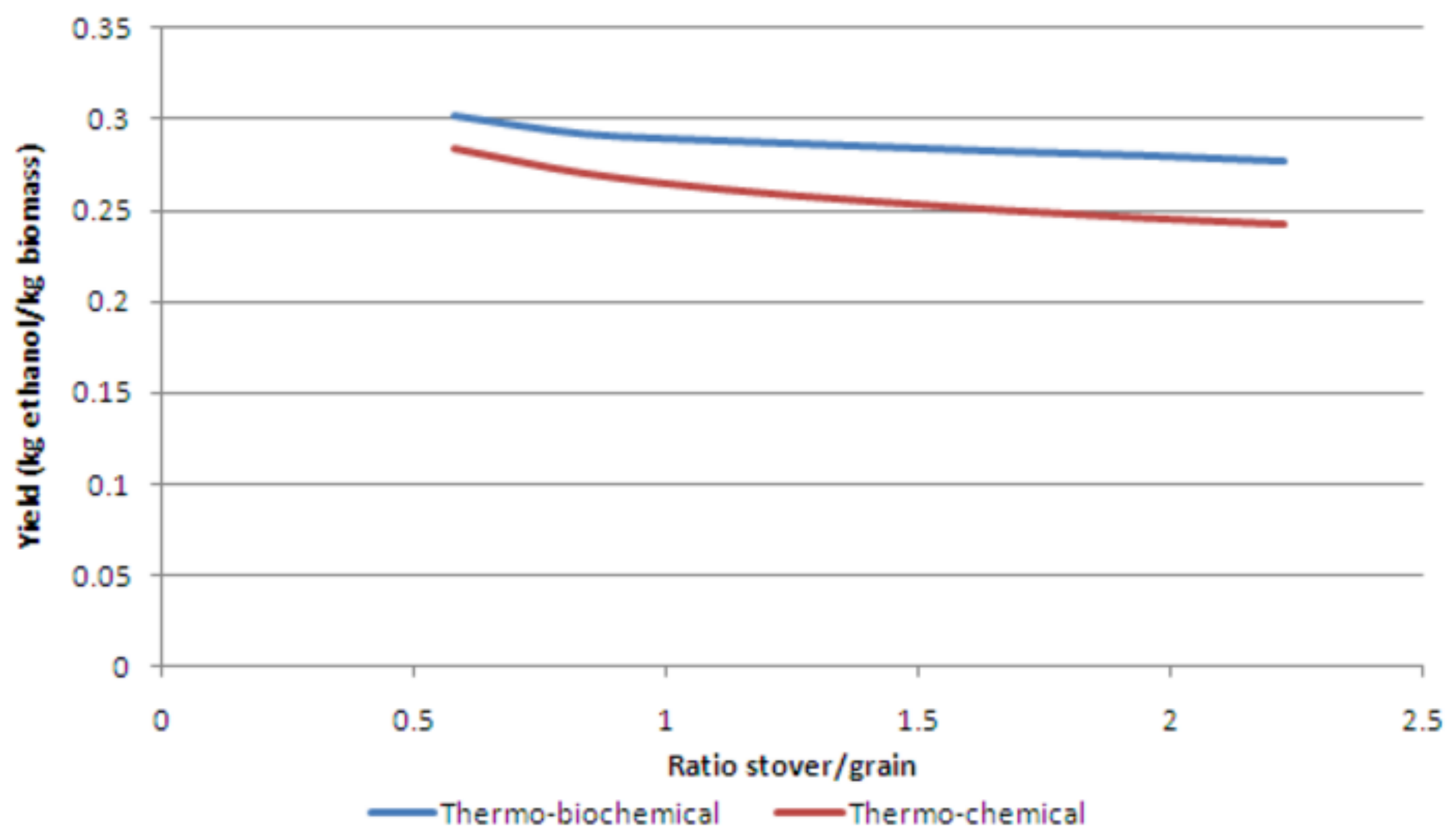


Click here to download high resolution image

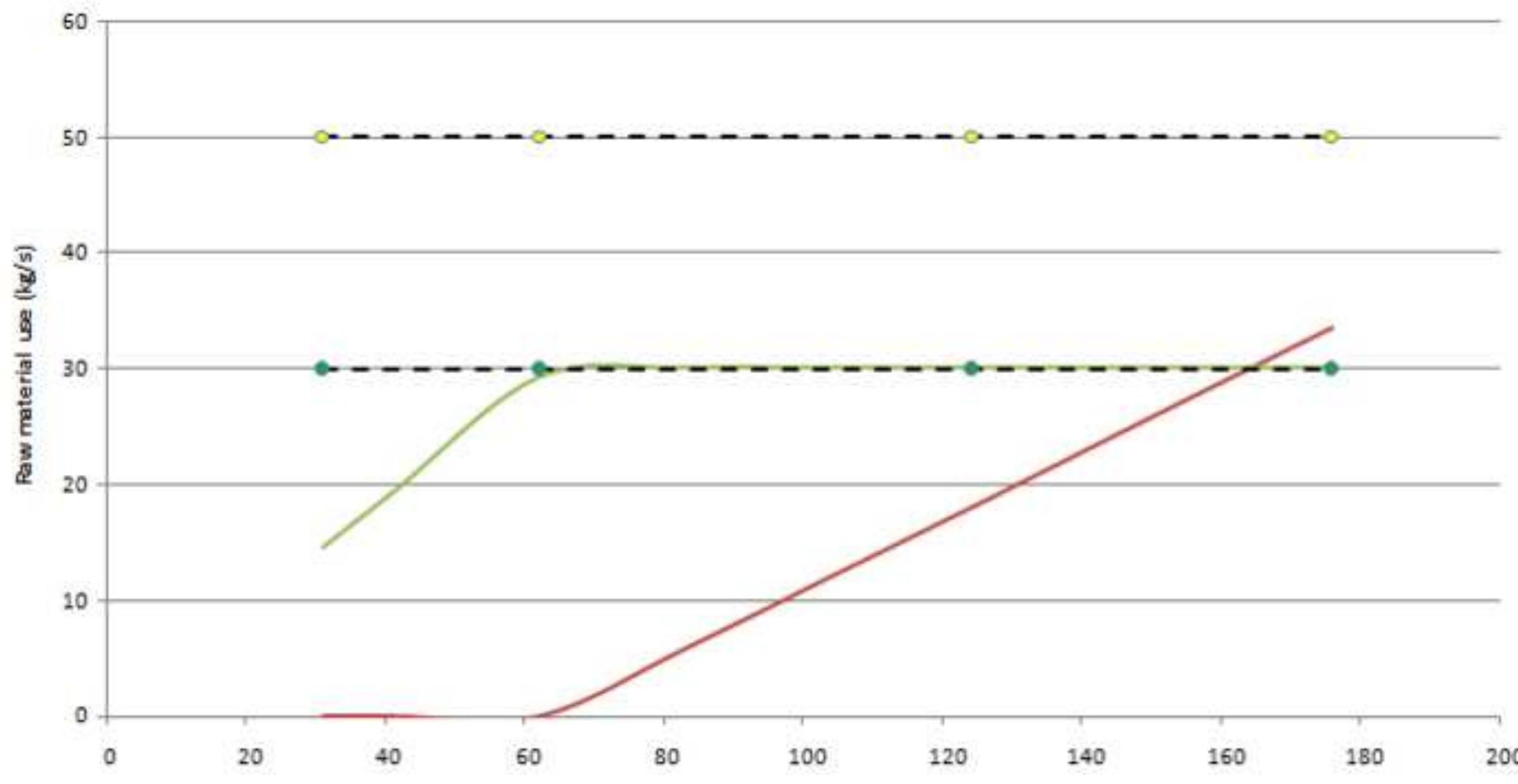

Ethanol production (Mgal/yr)

- - Grain available

Grain consumption integrated

Stover consumption Integrated

- - Stover available 
Click here to download high resolution image

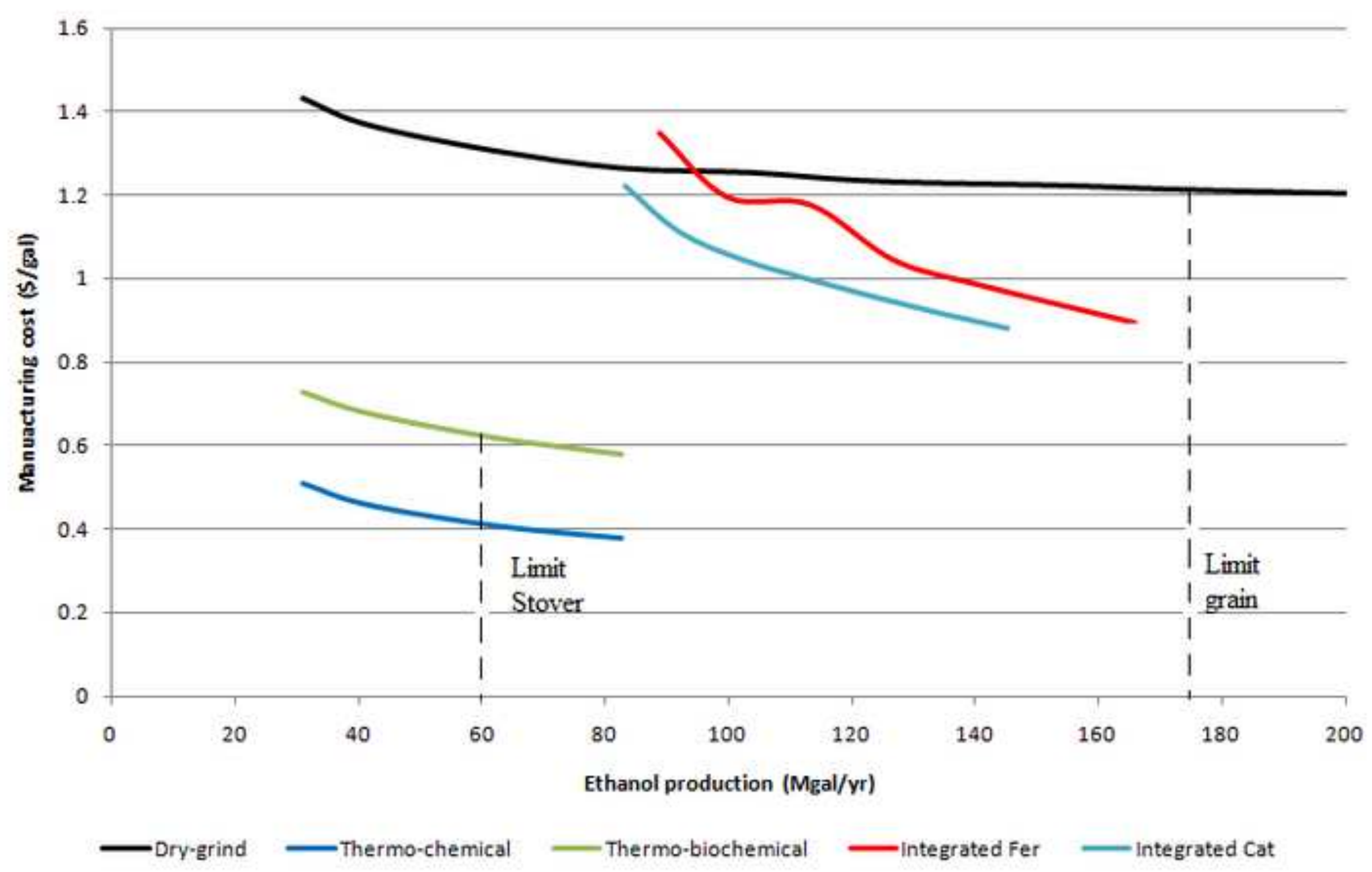

-Dry-grind Thermo-chemical - Thermo-biochemical - Integrated Fer - Integrated Cat 